F.N. Soto-Adames and S.J. Taylor - New species and new records of springtails (Hexapoda: Collembola) from caves in the Salem Plateau of Illinois, USA. Journal of Cave and Karst Studies, v. 75, no. 2, p. 146-175. DOI: 10.4311/2011LSC0257

\title{
NEW SPECIES AND NEW RECORDS OF SPRINGTAILS (HEXAPODA: COLLEMBOLA) FROM CAVES IN THE SALEM PLATEAU OF ILLINOIS, USA
}

\author{
Felipe N. Soto-Adames and Steven J. Taylor \\ Illinois Natural History Survey, University of Illinois at Urbana-Champaign, 1816 S. Oak St., Champaign IL 61820 USA, \\ fsoto@illinois.edu,sjtaylor@illinois.edu
}

\begin{abstract}
The springtail (Hexapoda: Collembola) fauna of eight caves (Wizard Cave, Pautler Cave, Spider Cave, Wanda's Waterfall Cave, Illinois Caverns, Stemler Cave, Hidden Hand Cave, and Bat Sump Cave) in the Salem Plateau of southwestern Illinois (Monroe and St. Clair counties) was surveyed in 2009 using a combination of methods, including pitfall traps, Berlese-funnel processing of litter, and hand collections by quadrat, on drip pools, free standing bait, and random locations. In total, forty-nine species of springtails were found. Four are described as new to science (Onychiurus pipistrellae n. sp., Pygmarrhopalites fransjanssens $\mathrm{n}$. $\mathrm{sp}, P$. incantator $\mathrm{n} . \mathrm{sp}$, and $P$. salemensis n. sp), four may represent new species but there is insufficient material available to prepare full descriptions (two species in the genus Superodontella, one in Pseudachorutes, one in Sminthurides), and three others (Ceratophysella $\mathrm{cf}$. brevis, C. cf. lucifuga, and Folsomia cf. bisetosa) are identified to species, but differences from the nominal species suggest further studies may indicate the Illinois populations represent distinct forms. In addition, five other species represent new records for Illinois, and eighteen are new cave records for the species in North America. The new records more than double the number of springtails species known from caves in the Salem Plateau region. More than half (twenty-nine) of the species reported are ranked as rare (S1-S2) at the state level. The total number of springtail species in Salem Plateau caves could be more than twice what is recorded in the present study, and more new species and state records should be found when caves in other Illinois karst regions are more thoroughly examined.
\end{abstract}

\section{INTRODUCTION}

Illinois's karst is distributed across five regions (Fig. 1) that contain numerous sinkholes, springs, and shallow groundwater conduits. Four of these regions-Driftless Area, Lincoln Hills, Salem Plateau, and Shawnee Hillscontain caves accessible to humans. In addition to their hydrological, recreational, geological, and cultural values, these caves contain fascinating assemblages of life. The fauna most familiar to the public are bats and salamanders, but caves also contain a wide variety of invertebrates. Among these are the Illinois cave amphipod, Gammarus acherondytes Hubricht and Mackin, which is federally listed as endangered, the enigmatic cavesnail, Fontigens antrocetes (Hubricht), a state-listed species, and a singlesite endemic Illinois cave beetle Pseudanophthalmus illinoisensis Barr and Peck. One cave springtail, Pygmarrhopalites madonnensis (Zeppelini and Christiansen), is listed as state-endangered in Illinois. Numerous other invertebrate species occur in Illinois caves, including a variety of other springtails (Collembola).

Springtails are small hexapods characterized by the presence of four-segment antennae, a six-segment abdomen, a large vesicle (the ventral tube) on the ventral part of the first abdominal segment, and, in many species, a jumping-organ complex formed by the tail-like furcula and the furcula catch or retinaculum. Springtails are most commonly found in soil and leaf litter, but they have invaded other specialized habitats, including caves. Many soil or leaf-litter species are commonly found in caves as xenobionts, but some species are cave-adapted or cavelimited and do not sustain surface populations (Christiansen and Culver, 1987).

In Illinois, the most common families of Collembola reported from caves are Hypogastruridae, Onychiuridae, Oncopoduridae, Tomoceridae, Isotomidae, Entomobryidae, and Sminthuridae sensu lato. Of the forty-three species of springtails previously recorded from Illinois caves, slightly more than $25 \%$ (eleven species) are either troglobionts (obligatorily permanent residents of subterranean habitats) or eutroglophiles (facultatively permanent residents of subterranean habitats). The genera of eutroglophiles or troglobionts reported from Illinois prior to our study are Typhlogastrura, Lethemurus, Oncopodura, Pseudosinella, Sinella, Pygmarrhopalites, and Arrhopalites. Pygmarrhopalites sapo (Zeppelini and Christiansen) and Pygmarrhopalites madonnensis (Zeppelini and Christiansen) are the only species of cave springtails currently known to be endemic to Illinois. The number of endemics is probably higher than current inventories would suggest, 


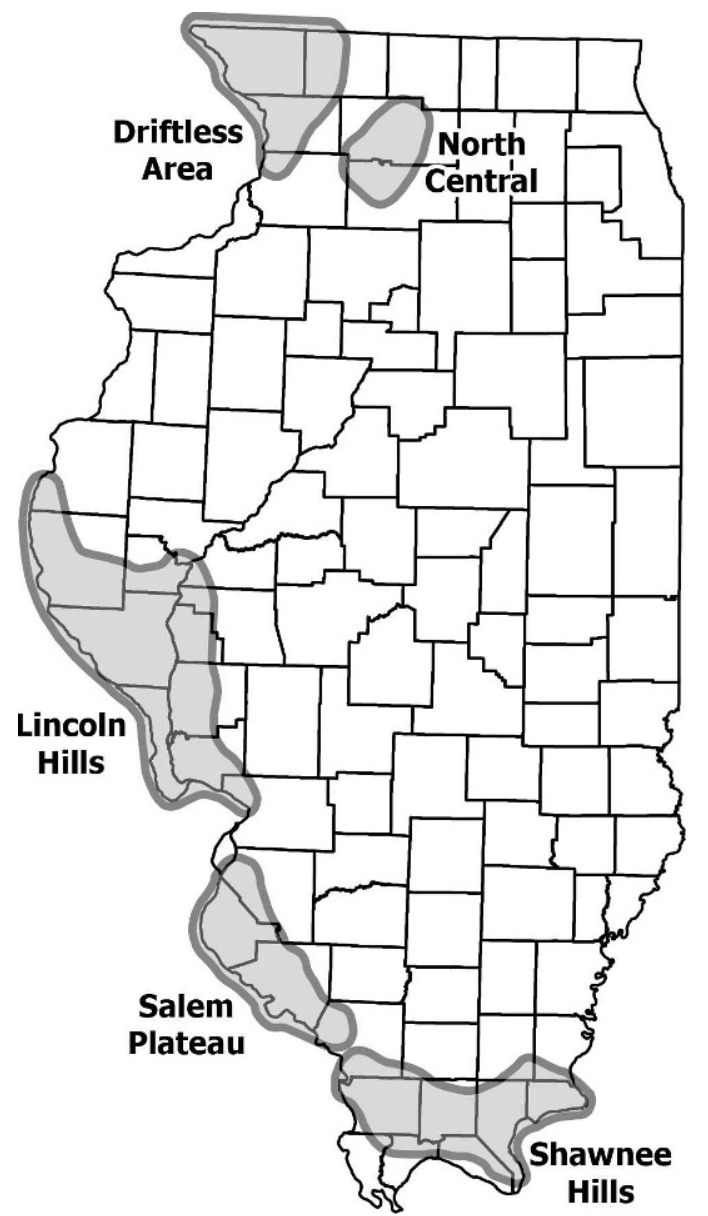

Figure 1. Illinois karst areas, adapted from Weibel and Panno (1997) and Panno et al. (1997).

as most groups have not been studied in detail. For example, the genera Typhlogastrura and Pseudosinella have diversified extensively in caves elsewhere in North America and Europe, and although both are reported from Illinois caves, no species from either genus has been identified for the state. In addition, some eutroglophiles and troglobionts first thought to be widely distributed across karst regions are now known to represent complexes of species endemic to just a few caves. The most striking example of this is the Onychiurus reluctus species complex, in which five species were recently identified (Pomorski et al., 2009).

This report presents findings from an inventory of springtails collected in eight caves in Illinois's Salem Plateau.

\section{Methods}

\section{Field SAmpling}

At each cave, the dominant habitat types in which springtails might occur were sampled. Collections were made using Limburger cheese-baited pitfall traps partially filled with 95\% ethanol, Berlese-funnel processing of litter samples, and hand sampling using an aspirator either in a

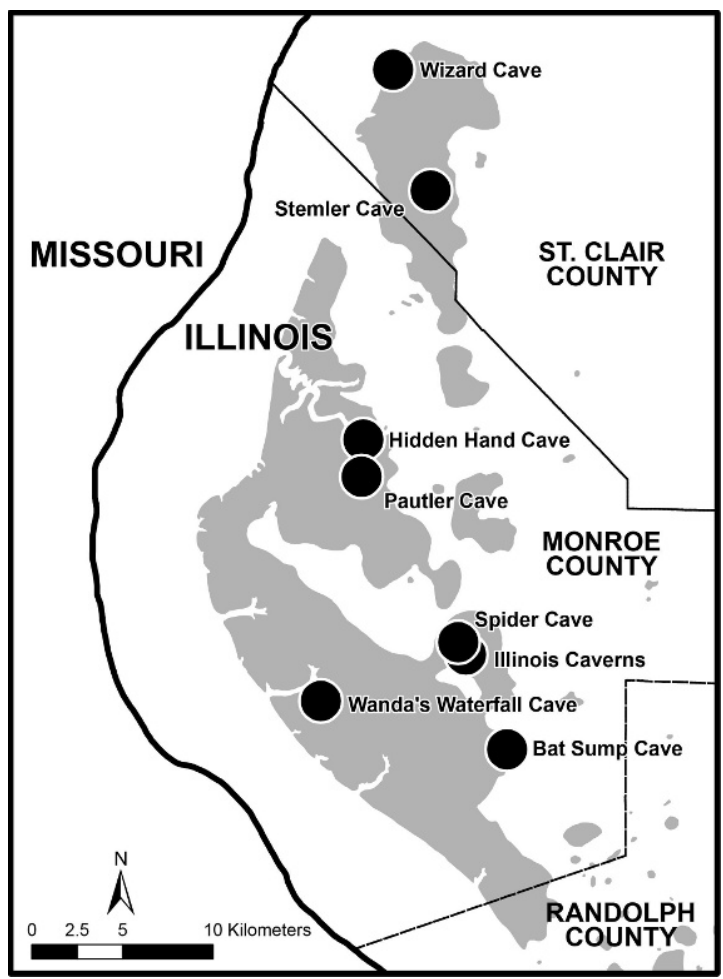

Figure 2. Distribution of eight Illinois caves where springtails were collected during 2009. Gray shading indicates approximate boundaries of karst based on sinkhole mapping (Illinois State Geological Survey). Cave locations are approximate.

structured fashion (timed search of drip pools and quadrat searches on cave floors and walls) or by general inspection around haphazardly placed cheese smears and other potential sources of energy such as animal scats and rotting logs. All specimens were preserved in 95\% ethanol.

Eight caves were selected for study in the Salem Plateau (Fig. 2). All necessary permits required to conduct the research were obtained prior to the beginning of fieldwork. The collection dates given below include the period during which pitfall traps were exposed in the field. Litter samples to be processed in Berlese funnels in the laboratory were usually collected during the second visit to a cave. Collection information for each cave is as follows:

USA: IL: St. Clair Co.: Wizard Cave, Dupo, near Falling Spring, 15-17 June 2009, SJ Taylor, FN SotoAdames, and CA Phillips.

USA: IL: Monroe Co.: Pautler Cave, $3.0 \mathrm{mi}$ WSW of Waterloo, 14-16 September 2009, SJ Taylor, and FN Soto-Adames.

USA: IL: Monroe Co: Wanda's Waterfall Cave, 7.4 mi SE of Valmeyer, 15-17 September 2009, SJ Taylor and FN Soto-Adames.

USA: IL: Monroe Co: Spider Cave, $6.5 \mathrm{mi} \mathrm{S}$ of Waterloo, 15-17 September 2009, SJ Taylor and FN SotoAdames.

Journal of Cave and Karst Studies, August 2013•147 
USA: IL: Monroe Co: Illinois Caverns, 24-26 September 2009, SJ Taylor, FN Soto-Adames, A Kuhns, E Zaborski, J Jacoby, A Paprocki, and M Pessino.

USA: IL: St. Clair Co: Stemler Cave, $2.7 \mathrm{mi} \mathrm{NE}$ of Columbia IL, 28-30 September 2009, SJ Taylor and FN Soto-Adames.

USA: IL: Monroe Co: Hidden Hand Cave, $3 \mathrm{mi} \mathrm{W}$ of Waterloo, 14-16 October 2009, SJ Taylor and FN Soto-Adames.

USA: IL: Monroe Co: Bat Sump Cave, $6.6 \mathrm{mi}$ WSW of Red Bud, 3-5 November 2009, SJ Taylor and FN Soto-Adames.

\section{Notes to Species Descriptions, Ecological}

Classification and Distributional Ranking

The nomenclature of the chaetotaxy in Ceratophysella and Superodontella follows Fjellberg (1985) and Jordana et al. (1997), respectively. The chaetotaxy of Pseudosinella follows Szeptycki (1979) and Soto-Adames (2010).

Nomenclature of the chaetotaxy of the head and small abdomen in Pygmarrhopalites follows Christiansen and Bellinger (1998). The identity of head vertical setae M4 and M5 appears confusing in the literature. We consider M5 to form a row with L2 and IL3 (row D in Betsch and Waller, 1994), whereas M4 forms a row with L1 and IL2 (row C in Betsch and Waller, 1994). None of the species of Pygmarrhopalites reported here carries seta M5, but the clarification is noted because $P$. hirsuta (Christiansen) has been described as having M5 and lacking M4, but an individual identified as representing this species (Zeppelini et al., 2009) examined by us carries M4 (by our convention) instead of M5. The nomenclature of distal setae in rows D and $\mathrm{E}$ on the lateral valve of the small abdomen is confusing. We have identified as E7 the seta labeled E8 in Christiansen and Bellinger (1998) because in all individuals examined by us the socket of this seta aligns with D7 (when present) and C7 instead of D8 and C8 (Figs. 15C, F). Seta D9 is always longer than setae D7-D10 and can be used as a reference point when some setae in the series are absent.

Abbreviations used throughout the descriptions are Ant., PAO, Th., and Abd. for antennal segment, post antennal organ, thorax, and abdomen, respectively.

Types of the new species described here and vouchers for all previously named species are deposited in the Illinois Natural History Survey Insect Collection.

We assigned each species to an ecological classification following Culver and Pippan (2009), and Sket (2008), instead of the system utilized by Barr $(1963,1968)$, which is more familiar to North American speleologists. The ecological categories considered are: troglobiont (TB obligate and permanent residents of subterranean habitats), eutroglophile (EU - facultatively permanent residents of subterranean habitats also found in other habitats), subtroglophile (SU - obligate or facultative residents of subterranean habitats that utilize other habitats for some portion of life cycle) and trogloxene (TX - sporadic residents of subterranean habitats ["accidental" of Barr 1963, 1968]).

Rankings of the species below provide a measure of the extent of a species distribution at the state (S) and global (G) level. Rankings are circumscribed following NatureServe conservation status ranks (Master et al., 2009): For state and global imperilment, species reported in five or fewer localities are ranked S/G1; six to twenty localities, S/ G2; twenty-one to one hundred localities, S/G3; uncommon but not rare, with some cause for long-term concern due to declines or other factors, S/G4; and widespread and common, S/G5. Species introduced from other biogeographic regions are indicated with IN. These rankings are based on Illinois and North American records obtained from either the Collembola of North America (Christiansen and Bellinger, 1998) or the database of North American Collembola records (Christiansen, 2012). Additional sources of distributional information are listed under individual species accounts.

\section{Species Accounts}

\section{HYPOGASTRURIDAE}

Hypogastrura pannosa (Macnamara), 1922 - TX S1/G5; New Illinois Record

Localities: Wanda's Waterfall Cave, Stemler Cave

Hypogastrura pannosa is part of a species complex that includes H. essa, H. matura, and the Palearctic H. assimilis. Hypogastrura pannosa may be a junior synonym of $H$. assimilis (Babenko et al., 1994; Thibaud et al., 2004), but we follow previous workers (Fjellberg, 1985; Christiansen and Bellinger, 1998) in assigning the epithet pannosa to North American populations having a PAO with four papillate arms, mucronal lamella ending abruptly subapically, and Abd. 4 with sensillum-like seta p5.

This species is widespread in North America, but this is the first report from Illinois. It is possible that previous Illinois reports of either $H$. matura or, more likely, $H$. essa actually refer to $H$. pannosa. There is one previous report from Kentucky caves.

Ceratophysella boletivora (Packard), 1873 - TX S2/G5 Localities: Wanda's Waterfall Cave, Illinois Caverns, Bat Sump Cave

As circumscribed by Christiansen and Bellinger (1980), based on the lectotype, this species is characterized by having Abd. 4 seta p2 clearly longer than p1 and with 7-9 (depending on the position of a5) microsetae internal to a line drawn across a6-p4 (Fig. 3A), tenent hairs capitate, Yoshii "a" measure 16-18, Ant. 4 apical bulb bilobed, and distal inner dental setae only weakly enlarged basally. The species is easy to identify in alcohol by having rust-red head and antennae, and, usually, patternless dark blue to black body.

Ceratophysella boletivora was previously reported from non-cave sites in Cisco, Markham, and Cook counties in 

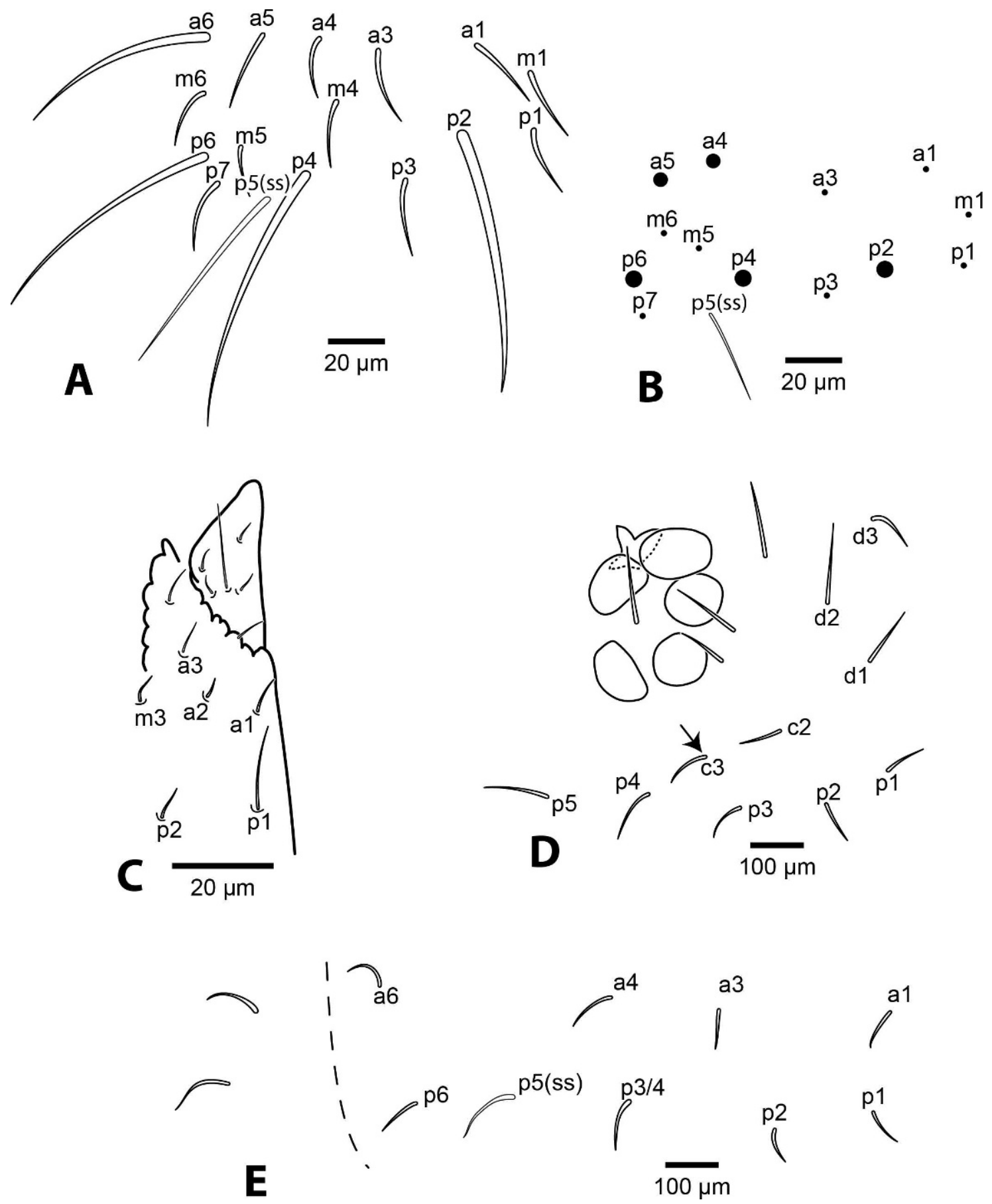

Figure 3. Dorsal chaetotaxy of fourth abdominal segment: (A) Ceratophysella boletivora; (B) Ceratophysella cf. brevis, filledin circles represent macrosetae, dots represent regular acuminate seta. Superodontella sp. 1: (C) labium and postlabium; (D) dorsal chaetotaxy of left side of head, arrow points to seta absent in S. substriata; (E) dorsal chaetotaxy of first abdominal segment.

Illinois. This species has been reported from caves in Missouri, but this is the first record for the species in Illinois caves.

Ceratophysella $\mathrm{cf}$. brevis Christiansen and Bellinger, 1980 — EU S1/G5; New Illinois Record

Localities: Wanda's Waterfall Cave, Bat Sump Cave
We identify as C. cf. brevis all individuals showing characters of the $C$. denticulata species complex as defined by Christiansen and Bellinger (1980), but with anterior lobes of PAO less than $1.5 \times$ the length of posterior lobes and inner distal dental setae not sharply bent or basally enlarged. Our specimens are light blue dorsally and white ventrally instead of dark blue to black as pointed out by 
Christiansen and Bellinger (1980) and Fjellberg (1985) for Alaskan populations. We examined eleven specimens, six from Wanda's Waterfall and five from Bat Sump, and all have acuminate serrate macrosetae, seta $\mathrm{m} 6$ present on $\mathrm{Th}$. 2-3, and lack seta $\mathrm{m} 3$ on Abd 1-4 (Fig. 3B). Most individuals also lack seta $\mathrm{m} 4$ on Abd. 1-3, although four specimens (two from each cave) carry this seta on at least one of the abdominal segments.

Fjellberg (1985) reported two forms of C. brevis from Alaska: one form should be easy to identify as $C$. brevis by the absence of coarsely serrated setae and absence of setae $\mathrm{m} 6$ on Th. 2-3, and m3-4 on Abd. 1. The second form has coarse body seta, and all the thoracic and abdominal setae mentioned above are present. This second form would differ from $C$. engadinensis only in the proportion of anterior to posterior PAO lobes and in not having sharply bent setae on the dens. Our specimens do not match either of Fjellberg's forms or the original description of the species in details of the dorsal chaetotaxy of the body and may represent a different species altogether. However, the significance of the morphological variation observed among populations included in the $C$. denticulata species complex remains unclear, and some other source of information may be required to sort discrete units within the group.

This report represents the first record of Ceratophysella cf. brevis from Illinois. C. brevis was originally described from surface habitats in Wyoming, but now it is also known from Alaska (Fjellberg, 1985) and from caves in Kentucky, California, and Indiana. In addition to the North American records, the species has been reported from Siberia (Babenko et al., 1994).

Ceratophysella denticulata (Bagnall), 1941 - EU S5/G5

Localities: Illinois Caverns, Stemler Cave

The individuals sampled in Illinois Caverns have a welldeveloped antennal file and coarsely serrate, capitate macrosetae. Ceratophysella denticulata is a common species, widely distributed throughout the Northern Hemisphere (Christiansen and Bellinger, 1998; Thibaud et al., 2004). In Illinois $C$. denticulata has been previously identified from at least seven caves in Calhoun, Johnson, Union, and Monroe counties.

Ceratophysella engadinensis Gisin, 1949 - EU/TX S?/G5; New Illinois Record

Locality: Illinois Caverns

This is another species widely distributed throughout the temperate zone of the Northern Hemisphere. Ceratophysella engadinensis differs from $C$. denticulata only in the absence of seta $\mathrm{a}^{\prime}$ on Abd. 5 (Christiansen and Bellinger, 1998; Fjellberg, 1998). Although the species has not been previously reported from Illinois, it is likely that in the past it has been confused with or included as part of $C$. denticulata; the individuals collected in Illinois Caverns were found mixed-in among many specimens of $C$. denticulata. However, we recognize both species based on recent hybridization studies that suggest the two forms are reproductively isolated by postembryonic isolation mechanisms (Skarżyński, 2005).

Ceratophysella cf. lucifuga (Packard), 1888 - TB S1/G1; New Illinois Record

Locality: Wanda's Waterfall Cave

The species lacks pigment, but retains all eyes, and there is little change in the relative length of antennae and claw, or in the development of sensory organs.

One subadult male (1.2 $\mathrm{mm}$ long) and two juveniles ( 0.89 and $0.69 \mathrm{~mm}$ ) were examined, and they differ from $C$. lucifuga, as redescribed by Skarżyński (2007), in not having pigment on the eye patch (individuals appeared to be blind under the dissecting microscope), in having an undivided apical lobe on Ant. 4 (trilobed in C. lucifuga), in having 4-6 differentiated sensilla on the ventral file of Ant. 4 (15 in $C$. lucifuga), and in the presence in the Illinois specimens of a supplementary seta between p5 and p6 on Abd. 4. The male does not have inner ungual teeth, but the two juveniles have a clear inner ungual tooth on all legs. Seta m4 is absent on Abd. 1-3 and present on Abd. 4 of the subadult; $\mathrm{m} 4$ is present on all abdominal segments in the juveniles.

Up to the present report, C. lucifuga was known only from three caves in Crawford and Harrison counties, Indiana. The physical distance $(\approx 330 \mathrm{~km})$ and morphological differences between the Illinois and Indiana populations suggest they may represent distinct species, but additional material from Illinois will be needed to determine if the morphological differences noted here are fixed.

Xenylla welchi Folsom, 1916 - TX S5/G5

Locality: Stemler Cave

This cosmopolitan species occurs throughout North America and Eurasia in surface leaf litter (Thibaud et al., 2004).

\section{Odontellidae}

Superodontella cornifer (Mills), 1934 - TX S1/G5 Locality: Bat Sump Cave

This species is widely distributed throughout North America and was previously reported from Hardin County, Illinois. However, this is the first record of the species from an Illinois cave. This individual is a small juvenile with only 4 dental setae.

Superodontella substriata (Wray), 1953 - TX S2/G2 Localities: Wanda's Waterfall Cave, Illinois Caverns

This species is characterized by having anal spines, body tubercles on head to Abd. 5 circular to somewhat polygonal in cross section, but forming ridges and valleys on Abd. 6; Ant. 4 with 7-8 blunt sensilla; and 2 clavate tenent hairs on each leg. In addition, the individuals from Illinois have dorsal head setae c3 present and c2 absent (arrow in Fig. 3D); 3 labial and 7 postlabial setae (Fig. 5A); chaetotaxy of Th. 2-3 as in S. shasta but with 


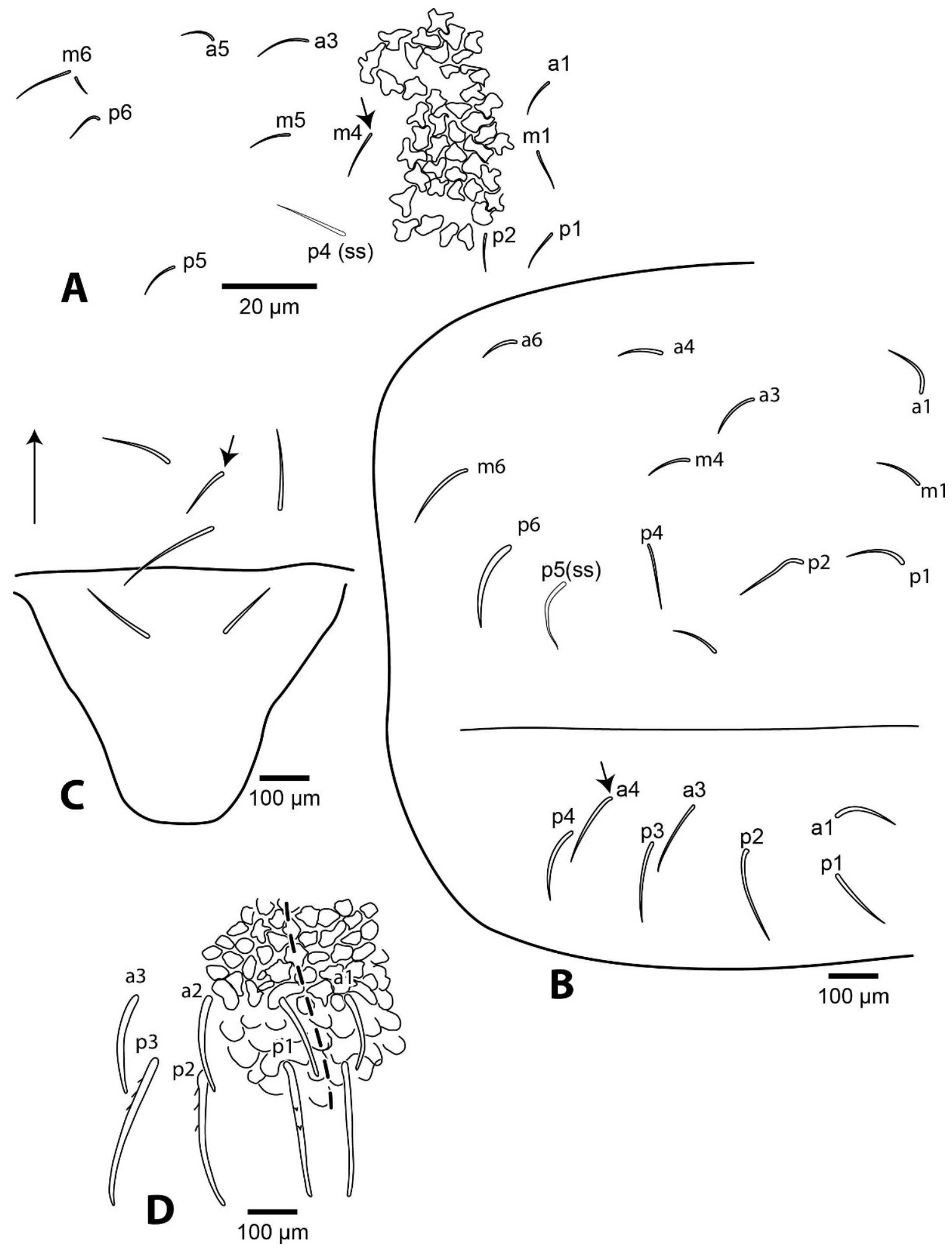

Figure 4. Chaetotaxy of Superodontella sp. 1, short arrows point at setae absent in S. substriata: (A) mesothorax; (B) abdomen 4-5; (C) sterna of abdomen 3-4, long arrow points anteriorly; (D) cuticle sculpturing and structure of setae on abdomen 5 . 

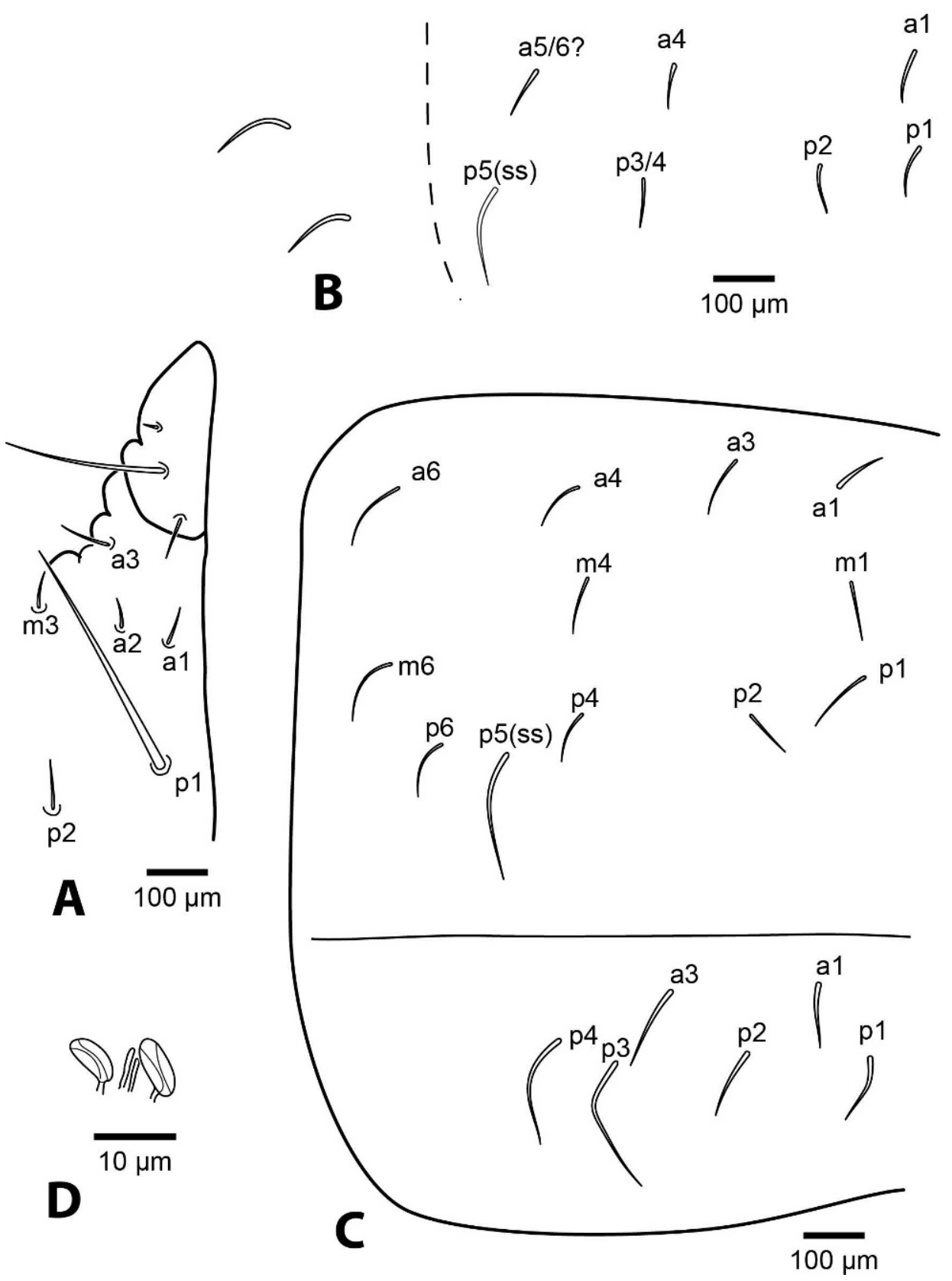

Figure 5. Chaetotaxy of Superodontella substriata: (A) labium and postlabium; (B) abdomen 1; (C) abdomen 4-5. Onychiurus pipistrellae n. sp.: (D) sensilla of third antennal segment sense organ.

seta $\mathrm{m} 4$ absent (arrow in Fig. 4A); Abd. 1-3 chaetotaxy reduced to 3 anterior and 4 posterior setae (Fig. 5B); Abd. 4 (Fig. 5C) with p5 clearly longer than p6; Abd. 5 with 2 anterior setae (Fig. 5C); sterna of Abd. 3-4 with 3 anterior and 2 posterior setae (arrow in Fig. 4C points at seta absent).

This is a forest leaf litter species originally described from Illinois, and it has been reported from Champaign, Clark, Jackson, Logan, and Pope counties. Additional records for the species include North Carolina, Connecticut, Quebec (Therrien et al., 1999), and British Columbia. This is the first record of this species from caves in Illinois.
Superodontella sp. 1 - TX? S1?/G1?

Locality: Wanda's Waterfall Cave

The single individual collected is similar to $S$. shasta in lacking anal spines, in having body tubercles angulate or polygonal in cross section dorsally on head and body, although on the posterior part of Abd. 5 the tubercles become rounded or circular (Fig. 4D), in having relatively short ungues, and in the presence of 6 blunt sensilla on Ant. 4. However, it differs from $S$. shasta in having a relatively blunt mouth cone (Fig. 3C), in having 1, 2, 2 clavate tenent hairs on the pro-, meso-, and metathoracic legs, respectively, and in that the longest posterior setae on Abd. 4 
are apically expanded to weakly blunt and serrate. Other potentially informative characters observed in the individual from Illinois, but unknown in S. shasta are 6 labial and 7 postlabial setae (Fig. 3C); dorsal head setae c2 and c3 present (Fig. 3D); Th. 2-3 setae a2 and a6 absent, and $\mathrm{m} 5$ present (Fig. 4A); Abd. 1-3 with 4 anterior and 5 posterior setae (Fig. 3E); Abd. 4 with seta a3 displaced posteriorly, and p6 as long as p5, but clearly thicker (Fig. 4B); Abd. 5 with 3 anterior setae (Fig. 4B); and sterna of Abd. 2-4 with 3, 4 and 2 setae, respectively (Fig. 4C, only Abd. 3-4 shown).

\section{Superodontella sp. 2- TX? S1/G1?}

Locality: Wanda's Waterfall Cave

The single individual collected in Wanda's Waterfall Cave is a juvenile and appears to represent a new species characterized by a very short furcula with only two dental setae, PAO with three arms, tenent hairs on all legs acuminate, anal spines well developed, body tubercles round or oval in cross section, and Ant. 4 with 7 welldifferentiated blunt sensilla and dorsal head row c only with seta c3 present. The species is dark blue and does not show characters typically present in cave-adapted species.

\section{NeAnURidae}

Pseudachorutes aureofasciatus (Harvey), 1898 - TX S5/G5 Locality: Stemler Cave

This widespread species is found in forest leaf litter from British Columbia and California to Pennsylvania and Florida. In Illinois the species has been reported from Calhoun, Johnson, and Union (Guthrie Cave) counties. Pseudachorutes aureofasciatus is also known from Hunter's Cave, Jackson County, Iowa.

\section{Pseudachorutes sp. - TX? S1/G1? \\ Locality: Wanda's Waterfall Cave}

The single individual collected in Wanda's Waterfall Cave appears to represent an undescribed species. This is a black species, without morphological adaptations to subterranean life. This is likely a surface leaf litter form accidentally found inside the cave. After this individual was identified as a potential new species, several collecting trips were made to Wanda's Waterfall, but no additional specimens were found.

Vitronura giselae Gisin, 1950 - TX IN?

Locality: Wanda's Waterfall Cave

This is probably an introduced species now common in moist woodchip beds in central Illinois. Vitronura giselae was first reported from North America by Christiansen and Bellinger (1998), although the species was known to be established on the continent before that (Richard Snider, Michigan State University, personal communication). In Illinois the species was previously observed in Champaign County by the senior author. This is the second record of $V$. giselae from North American caves; the species was already reported from Swamp River Cave, Tennessee.
Although this species has a reduced number of eyes and is white when preserved in alcohol, it is not a sub- or eutroglophile. Living specimens are bright orange and the reduced number of eyes is characteristic of the lineage.

\section{ONYCHIURIDAE}

Onychiurus pipistrellae n. sp. - TB? S1?/G1?

Material Examined: Holotype, INHS Collection Number: 551,651; USA, IL, Monroe Co, Bat Sump Cave, $6.6 \mathrm{mi}$ WSW of Red Bud, hand collected on cave floor, swarming around cheese bait, 3-5 November 2009, SJ Taylor and FN Soto-Adames; Female, slide mounted. The slide with the holotype also includes one individual of Heteraphorura subtenua (Folsom) and one individual of Folsomia stella Christiansen and Tucker. Paratypes, INHS Collection Number 551,652-56; 9 males and females on slides and 69 adults and juveniles of both sexes in alcohol with same collection information as holotype. Additional paratypes, INHS Collection Number 551,657-60; USA, IL, St. Clair Co, Stemler Cave, $2.7 \mathrm{mi} \mathrm{NE}$ of Columbia IL, hand collected on cave floor and drip pool, 28-30 September 2009, SJ Taylor and FN Soto-Adames; 3 mounted on slides and 5 in alcohol.

Etymology: The epithet refers to the type locality, Bat Sump Cave.

Description: Largest male and female $1.7 \mathrm{~mm}$ and 2.2 $\mathrm{mm}$ long, respectively. Subapical sensilla of Ant. 4 smooth, rounded and resting in a shallow pit; subapical invagination as is $O$. reluctus; basal sensilla longer than subapical. Ant. 3 sense organ with five guard setae, five papilla, two rods, and two smooth sensilla distally expanded and bent, with middle groove (Fig. 5D); basal sensilla shorter than basal sensilla on Ant. 4. Postantennal organ with 12-15 compound vesicles. Apical seta of outer maxillary lobe unilaterally coarsely serrate on apical third, sublobular plate with two appendages. Labial palp with 6 proximal setae; thickened-blunt terminal seta present only on papilla $\mathrm{A}$ and $\mathrm{B}$; papilla $\mathrm{E}$ with 3 guard setae. Dorsal pseudocelli 32/033/33353; ventral 2/000/1112; subcoxae 13 with 222 pseudocelli. Ventral parapseudocelli 00/000/ 11100 ? (view of the dorsal anal valve is obstructed in all individuals examined and the presence or absence of a parapseudocellus cannot be established). Ventral thoracic setae absent. Prothorax with eight setae. Dorsal chaetotaxy of Th. 2 and Abd. 1 as in Figures 6A and 6B; tip of macro- and mesosetae acuminate and wide (Fig. 6C); medial seta absent on Abd. 1 (Fig. 6B) and present on Abd. 4 (Fig. 6E); Abd. VI seta $\mathrm{a} 0$ absent and $\mathrm{p} 0$ present, spines strongly conical. Subcoxae 1-3 with 555 setae. Ventral tube with $6-7+6-7$ setae. Furcula scars with 4 short posterior setae in a single row (Fig. 6D), homology of other furcula-associated setae difficult to assess, as their arrangement varies asymmetrically within individuals. Dorsal anal valve with setae $\mathrm{a} 0$ and $\mathrm{c} 0$ present, seta $\mathrm{b} 0$ absent (Fig. 6F); lateral anal valves with 4 hr, 6 inner, 4 medial and 5 outer setae (Fig. 7A). Pro- and metathoracic 

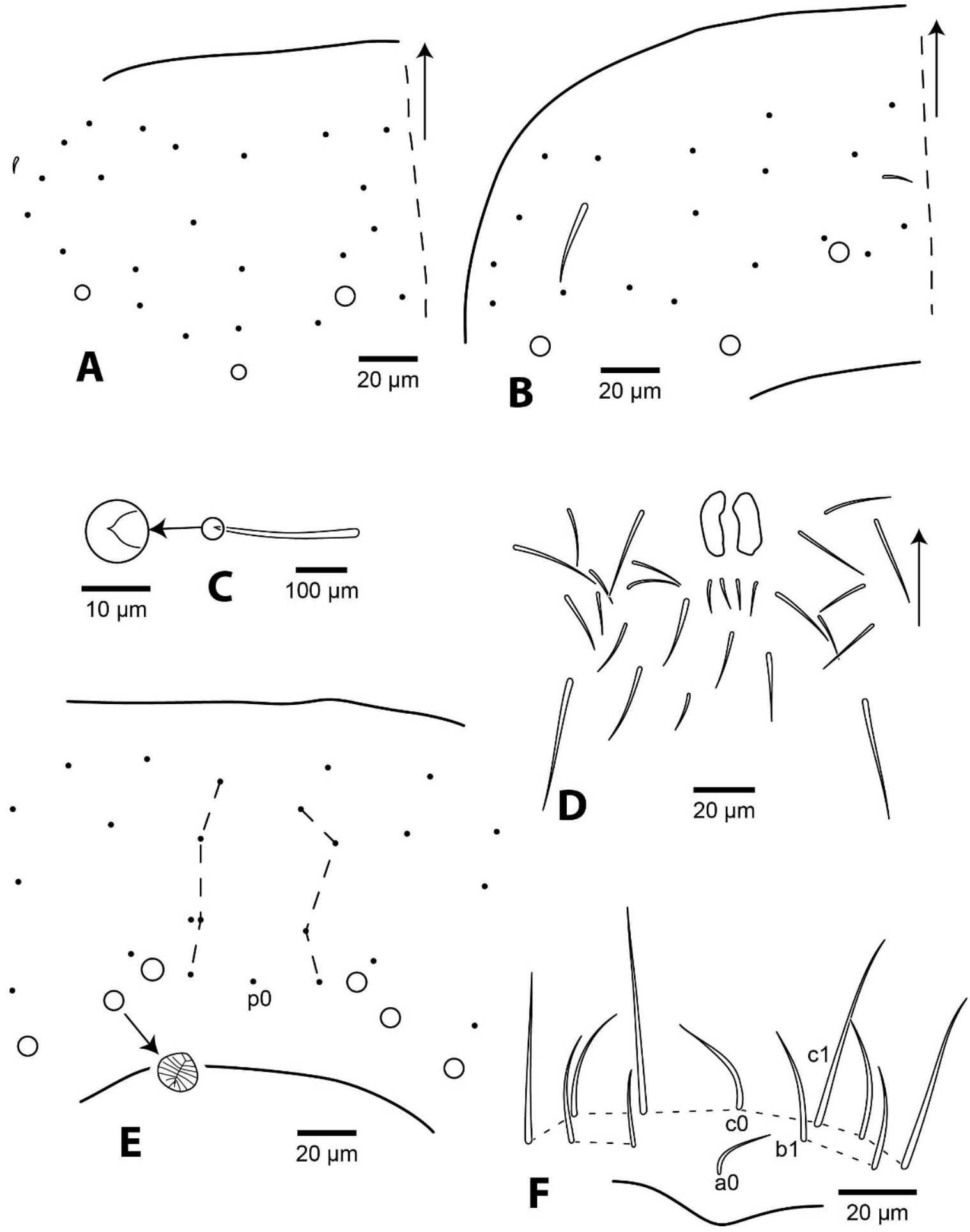

Figure 6. Onychiurus pipistrellae n. sp., dots represent setae and circles pseudocelli, long arrows point anteriorly: (A) dorsal chaetotaxy of mesothorax; (B) dorsal chaetotaxy of abdomen 1; (C) typical macroseta, arrow points at detail of apical end; (D) furcula scar and associated setae, arrow points to anterior end; (E) chaetotaxy of medial section of abdomen 4, arrow points at detail of pseudocelli ornamentation; (F) upper anal valve.

tibiotarsi with 9, 8, 1 setae in whorls A-C, respectively; mesothoracic tibiotarsus with 9, 8, 2 setae in whorls A-C (Figs. 7B, 7C); seta $\mathrm{M}$ present; tenent hair acuminate. Unguis with outer teeth, inner teeth absent. Unguiculus without basal lamella and as long as, to marginally longer than, inner edge of unguis.

Remarks: Table 1 summarizes differences between the new species and other North American members of the $O$. 


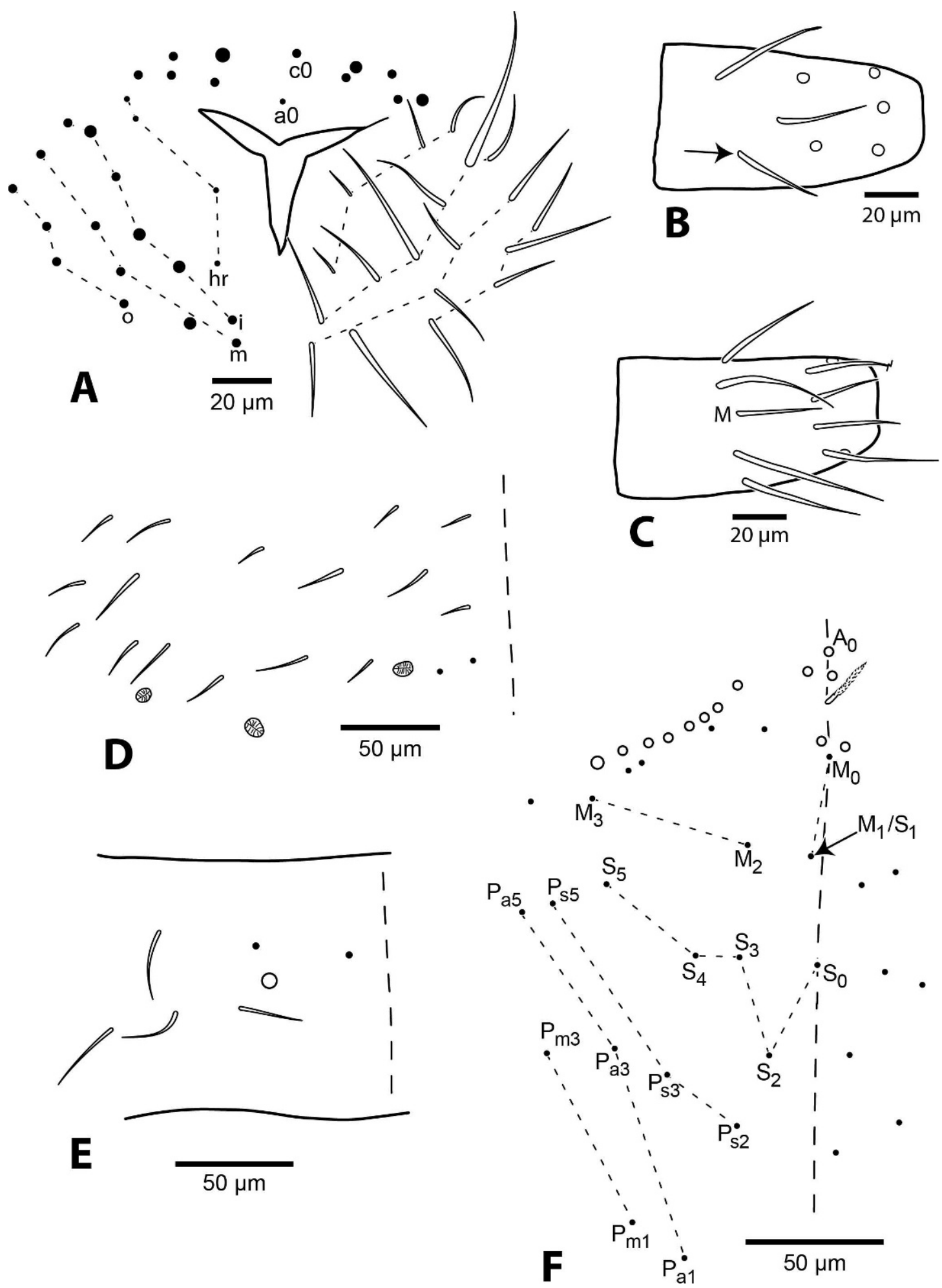

Figure 7. Chaetotaxy of Onychiurus spp., dots represent regular acuminate setae, dot diameter is roughly proportional to seta length: (A) $O$. pipistrellae $\mathbf{n}$. sp., anal valves; (B) $O$. pipistrellae $\mathbf{n}$. sp., mesothoracic tibiotarsus, anterior view, inner is toward top of figure, arrow indicates seta absent from pro- and metathoracic tibiotarsi; (C) $O$. pipistrellae n. sp., mesothoracic tibiotarsus, posterior view, inner is toward top of figure; (D) $O$. wilchi, abdomen 1 , syntype deposited at the Illinois Natural History Survey; (E) O. wilchi as above, but prothorax, circle represents pseudocellus; (F) Pseudosinella aera, dorsal head chaetotaxy, dots and open circles represent micro- and macrosetae, respectively. 


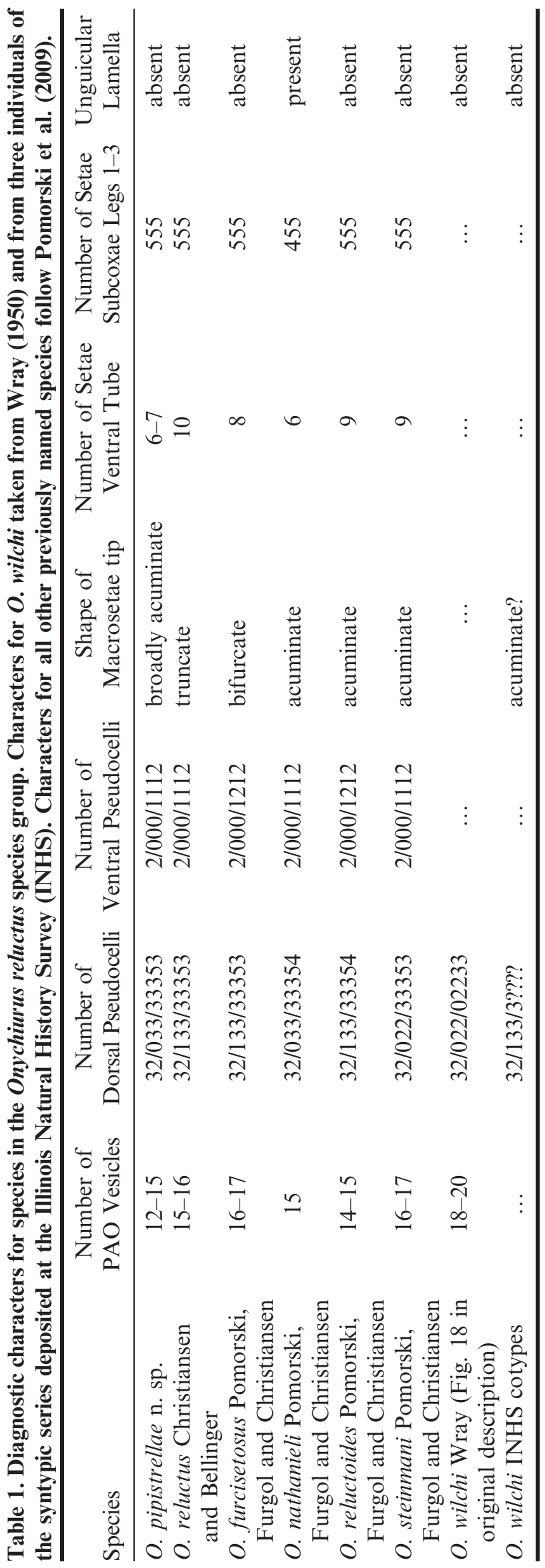

reluctus species complex. Most individuals of $O$. pipistrellae n. sp. will key out to O. steinmanni Pomorski, Furgol, and Christiansen, 2009 in Pomorski et al. (2009), but the new species is easily distinguished from $O$. steinmanni by the number of pseudocelli on Th. 2-3, the number of setae on ventral tube, the number of PAO vesicles, and, apparently, the number of proximal setae on the labial palp. The new species is most similar to O. reluctus Christiansen, 1961, from which it differs in lacking pseudocelli on Th. 1, the number of setae on the ventral tube, the shape of the macrosetal tip, and possibly the number of PAO vesicles. An adult female from Bat Sump cave has $1+1$ pseudocelli on Th. 1, but it retains the low number of setae on the ventral tube, the shape of the macrosetae, and a PAO with only 13 vesicles.

Onychiurus pipestrellae $\mathrm{n}$. $\mathrm{sp}$. was collected about 50 to $60 \mathrm{~km}$ southwest of the type locality of $O$. wilchi Wray, 1950. Following Wray's (1950) original description, the two species should be easy to distinguish by the combined absence of dorsal pseudocelli on Th. 1 and Abd. 1 in $O$. wilchi and the number of PAO vesicles. However, the syntypes of $O$. wilchi deposited at the Illinois Natural History Survey examined carry 1 and 3 pseudocelli on Th. 1 (Fig. 7E) and Abd. 1 (Fig. 7D), respectively. This suggests that $O$. wilchi is a senior synonym of either $O$. reluctus or $O$. pipistrellae n. sp. Unfortunately, the characters needed to decide between the alternatives (i.e., number of seta on the ventral tube, number of vesicles on the postantennal organ, and shape of the tip of the macrosetae) are not visible in the types studied, and the status of $O$. wilchi remains unresolved until fresh topotypical material is obtained.

The distribution of $O$. pipestrellae is unclear. The populations from Bat Sump and Stemler caves were previously sampled and identify as $O$. reluctus (Lewis et al., 2003). However, the redescription of $O$. reluctus by Pomorski et al. (2009) makes it clear that the population in Bat Sump and Stemler Cave represent a new species. It is possible that other records of $O$. reluctus in caves from southern Illinois (e.g., Fogelpole Cave, Hidden Hand Cave, Fults Saltpeter Cave), Missouri, and Kentucky may be referable to the new species. The five other described species in the $O$. reluctus species complex are found in caves in Virginia, Indiana, Wisconsin, Iowa, and Colorado.

Thalassaphorura encarpata (Denis), 1931 - EU S2/G5 Localities: Bat Sump Cave, Stemler Cave

This common species is widespread across North America. Thalassaphorura encarpata is known from Cumberland, Jackson, Johnson (Firestone Creek Cave), Piatt, and Wayne counties in Illinois. This species is relatively common in subterranean habitats, as it has been reported from caves in Missouri, Indiana, Texas, and Hawaii. 
Heteraphorura subtenua (Folsom), 1917 - EU S2/G5 Locality: Wanda's Waterfall Cave

This is part of a complex that includes three other species (H. bima, H.casa, and $H$. tala). The actual distribution of $H$. subtenua is unclear, as old identifications might have conflated the identity of all four forms. Confirmed records indicate the species ranges from Alaska and British Columbia to Maine and North Carolina, although it appears to be absent in the region between Iowa-Missouri-Arkansas and British Columbia. In Illinois the species has been reported from Alexander, Champaign, Coles, Jackson, La Salle, Union, Vermillion, and Washington counties. Heteraphorura subtenua has been previously reported from caves in Alaska, Illinois, Indiana, North Carolina, Texas, and West Virginia.

\section{TUllbergidae}

Mesaphorura silvicola (Folsom), 1932 - TX S1/G5

Localities: Wanda's Waterfall Cave, Bat Sump Cave

Mesaphorura silvicola is widespread in North America and common in surface leaf litter. In Illinois, M. silvicola is known from Jackson, Monroe, and Vermillion counties. The species was previously reported from a cave in Indiana.

\section{ISOTOMIDAE}

Hemisotoma thermophila (Axelson), 1900 - TX S1?/G5

Localities: Wanda's Waterfall Cave, Stemler Cave

This species is commonly found on surface leaf litter across temperate and tropical regions of the world (Potapov, 2001; Mari Mutt and Bellinger, 1990), and in Illinois it was previously known from Champaign County. This appears to be the first record for this species from Illinois caves.

Desoria trispinata (MacGillivray), 1896 - EU S5/G5

Localities: Wanda's Waterfall Cave, Illinois Caverns

This common surface species is widely distributed across temperate regions of the North Hemisphere (Potapov, 2001) and relatively common in cave leaf litter in North America. The individuals from the Salem Plateau have three instead of four labral papillae, a character shared with some populations from Missouri caves (Christiansen and Bellinger, 1998). The labral character may define an isolated population restricted to the Salem Plateau region on both sides of the Mississippi river.

Folsomia cf. bisetosa Gisin, 1953 - TX S1/G5; New Illinois Record

Locality: Stemler Cave

The single individual collected deep in Stemler Cave agrees with the description of $F$. bisetosa provided by Fjellberg (2007) in all characters except in having long unilaterally serrate macrosetae on all segments (macrosetae are smooth in $F$. bisetosa) and in having dorsal manubrial seta $\mathrm{mll}$ ( $\mathrm{mll}$ absent in $F$. bisetosa). This may be the same form identified as $F$. cf. bisetosa from Indiana by Waltz and Hart (1996). Folsomia bisetosa is distributed across the Old World arctic and subarctic regions, and its presence in an
Illinois cave seems unlikely. Additional material is needed to confirm the identity of the species.

Folsomia candida Willem, 1902 - EU S5/G5

Localities: Wanda's Waterfall Cave, Illinois Caverns, Bat Sump Cave, Stemler Cave

This is a common litter and soil species widespread in North American caves.

Folsomia prima Mills, 1931 - EU S2/G5

Localities: Illinois Caverns, Bat Sump Cave

This common surface leaf litter species is often found in caves. In Illinois the species has been reported from caves in Hardin County and from surface leaf litter in Champaign, Vermillion, and Williamson counties.

Folsomia stella Christiansen and Tucker, 1977 - EU S5/G5 Localities: Bat Sump Cave, Stemler Cave

This species is distributed across temperate North America and Eurasia (Potapov, 2001). In North America, $F$. stella is often found in caves. In Illinois, the species is previously known from Alexander, Champaign, Monroe, and Vermillion counties.

Folsomia variabilis Fjellberg, 1984 - TX S1/G5; New Illinois Record

Localities: Wanda's Waterfall Cave, Stemler Cave

This is the first record for $F$. variabilis from Illinois and from caves. The species was originally described from populations found in mosses at $11,000 \mathrm{ft}(3,400 \mathrm{~m})$ of elevation in Colorado (Fjellberg, 1984).

\section{Isotomiella minor Schäffer, 1896 - EU S5/G5}

Locality: Wizard Cave

This species is common in surface and cave habitats throughout North America.

Parisotoma notabilis (Schäffer), 1896 - EU S5/G5

Localities: Wanda's Waterfall Cave, Illinois Caverns, Hidden Hand Cave

Parisotoma notabilis is a common surface species, widely distributed across temperate regions of the Northern Hemisphere and probably the most common species of springtail in surface leaf litter in North America. The species is often found in caves.

Proisotoma sepulcralis Folsom, 1902 - TX S1/G1; New Illinois Record

Locality: Stemler Cave

This is the first record from Illinois and from caves for this uncommon species. Proisotoma sepulcralis was previously known only from Washington D.C., Michigan, and Pennsylvania.

TOMOCERIDAE

Lethemurus missus Mills, 1949 - TB S2/G2

Locality: Pautler Cave

This troglobiont is widespread in caves in the Salem Plateau. Lethemurus missus was originally described from 
Jersey County Illinois, but is now known to occur in Kentucky, Missouri, Alabama, Indiana, Virginia, and Colorado.

Pogonognathellus flavescens (Tullberg), 1871 species complex - EU S5/G5

Localities: Wizard Cave, Pautler Cave, Wanda's Waterfall Cave, Spider Cave, Illinois Caverns, Bat Sump Cave, Hidden Hand Cave, Stemler Cave

Species in the $P$. flavescens complex are the most common members of the family Tomoceridae in surface leaf litter and in caves in North America. Members of the $P$. flavescens complex appear to be widespread in North America and Europe. Until recently, all forms in the complex in North America were assigned to the nominal species, although the large amount of morphological variation reported from throughout its range suggested that it represented a species complex (Christiansen, 1964). Recently, Felderhoff et al. (2010) and Park et al. (2011) concluded that, based on molecular evidence, $P$. flavescens does not occur in North America and all or most forms previously identified as such are endemic to North America. Most species in the complex have been identified only by using molecular data, and just a handful of them have been diagnosed using morphological characters. Thus, the identity of the forms collected in the Salem Plateau caves will remain unclear until their DNA can be studied.

Pogonognathellus nigritus (Maynard), 1951 - TX S5/G5?; New Illinois Record

Localities: Spider Cave, Illinois Caverns, Bat Sump Cave

This is a common surface leaf litter species in wooded areas of the Salem Plateau. The actual distribution of $P$. nigirtus in North America is not known, because in the past it has been included as part of the variation of $P$. elongatus Maynard (Felderhoff et al., 2010), hence the question mark for global ranking. This is the first record for the species from caves.

\section{ONCOPODURIDAE}

Oncopodura iowae Christiansen, 1961 - TB/EU S2/G2

Localities: Wizard Cave, Wanda's Waterfall Cave, Illinois

Caverns, Hidden Hand Cave, Stemler Cave

This is the most common species of Oncopodura found in Illinois caves. Recent collections of this species on surface leaf litter (IL: Monroe Co., Valmeyer, Salt Lick Point, N 38.30644 W 90.30475, leaf litter between rock outcrops on bluff top, 13 May 2011, F.N. Soto-Adames) indicate the species can move freely above ground under appropriate conditions. The species has been previously reported from other localities in Monroe County, Illinois, and in caves in Iowa, Missouri, and South Dakota.

\section{ENTOMOBR YIDAE}

Pseudosinella aera Christiansen and Bellinger, 1980 - EU S2/G5

Locality: Wizard Cave
Complement to the description of $P$. aera based on individuals collected in Wizard Cave: Freshly killed individuals uniformly light blue, pigment more intense on eye patch. Scales present only on head, trunk, and coxae. Apical bulb of Ant. 4 absent; subapical sense organ "Y" shaped (Fig. 8A), appearing capitate in side view and in small individuals. Sense organ of Ant. 3 with main sensilla (i.e., numbers 2 and 3 in Chen and Christiansen, 1993) slightly bent, laterally expanded with dense central rachis (Fig. 8B); sensilla 1 and 4 longer, and sensillum 5 shorter, than sensilla 2-3; at least one lenticular organ present. Eyes 2+2. Dorsal head chaetotaxy as in (Fig. 7F): macrosetae A0, A2 and A3 present; A1 coarsely ciliate, but not a macroseta; other dorsal head setae narrow and smooth; M0 present, inserted almost between A3; row $\mathrm{S}$ with $4+1$ setae, S0 in line with S3; row Pa with 3 setae and bothriotrix $\mathrm{Pa} 6, \mathrm{~Pa} 5$ a microseta. Prelabral setae ciliate, all other setae smooth, labral intrusion and papillae not seen. Maxillar capitulum with four teeth. Sublobular plate of outer maxillary lobe with three seta-like appendages; subapical and apical setae smooth and subequal. Labial papila $\mathrm{E}$ with 4 guard setae, lateral appendage straight, blunt and reaching tip of papilla. Labial palp proximal setae $\mathrm{Y}$ and $\mathrm{Z}$ subequal. Labial triangle chaetotaxy with anterior setae smooth, posterior setae coarsely ciliate, except for $r$, which is acuminate, short and smooth; formula as M1M2rEL1L2A1-5 (Fig. 8C). All postlabial setae, except L2 and O1, coarsely ciliate; columns I, C, E, L and $\mathrm{O}$ with 4, 1, 2, 3, 2 setae, respectively; setae $\mathrm{L} 2$ and $\mathrm{O} 1$, smooth and acuminate as $\mathrm{r}$; one additional seta similar to $\mathrm{r}$ external to column $\mathrm{O}$. All pleural and peristomal setae coarsely ciliate, pss1-2 bothriotrix-like. Trunk macrosetae formula $00 / 0100+2$. Mesothoracic hood not developed, collar formed by $2-3$ rows of acuminate to weakly apically bent macrosetae. Mesothorax not polychaetotic. Metathorax without $\mathrm{p} 2 \mathrm{p}$, but otherwise with a full complement of setae; setae p2 less than $2 \times$ the length of a3. Abd. 1 with 10 posterior setae (Fig. 8D) arranged in a single row, but not evenly distributed along row, seta a3 inserted very close to $\mathrm{m} 3$ and $\mathrm{a} 5$ to $\mathrm{m} 4$; $\mathrm{a} 6$ present, not paired to sensilla as. Abd. 2 (Fig. 8E) with mi, ml, Lm, and $\mathrm{Ll}$ fan-shaped; a2, a3, $\mathrm{a} 2 \mathrm{p}, \mathrm{m} 4$, and $\mathrm{p} 5 \mathrm{p}$ ciliate, all other setae either denticulate or smooth; a3 inserted near and reaching as; $\mathrm{m} 3$ and $\mathrm{m} 5$ macrosetae, a6 present. Th. 3 (Fig. 8F) with a2, a6, am6, and all supplementary setae fan-shaped; a3 not reaching as; as half the length of $\mathrm{m} 3$; $\mathrm{d} 2$ present, a7 inserted anterior to and reaching am6; $\mathrm{m} 7$ smooth microseta inserted in row with $\mathrm{p} 5 ; \mathrm{p} 7$ a ciliate microseta; $\mathrm{m} 7$ enlarged. Bothriotrichal complex of Abd. 4 (Fig. 9A) with seta s present and fanshaped; a, m, D1, Pi, and Pe fan-shaped; C1p, T3, and D1p ciliate. Other chaetotaxy of Abd. 4 as in Figure 9B: B5 and B6 macrosetae, B5 inserted just anterior or on the line between A5-C2; C1 a smooth microsetae; D3, E2, E3, F1, and F3 large macrosetae; T6, T7, D2, and E1 small macrosetae; F2 a microsetae; microsetae posterior to E3 present; posterior setae $3+3$. Trochanteral organ with 23 


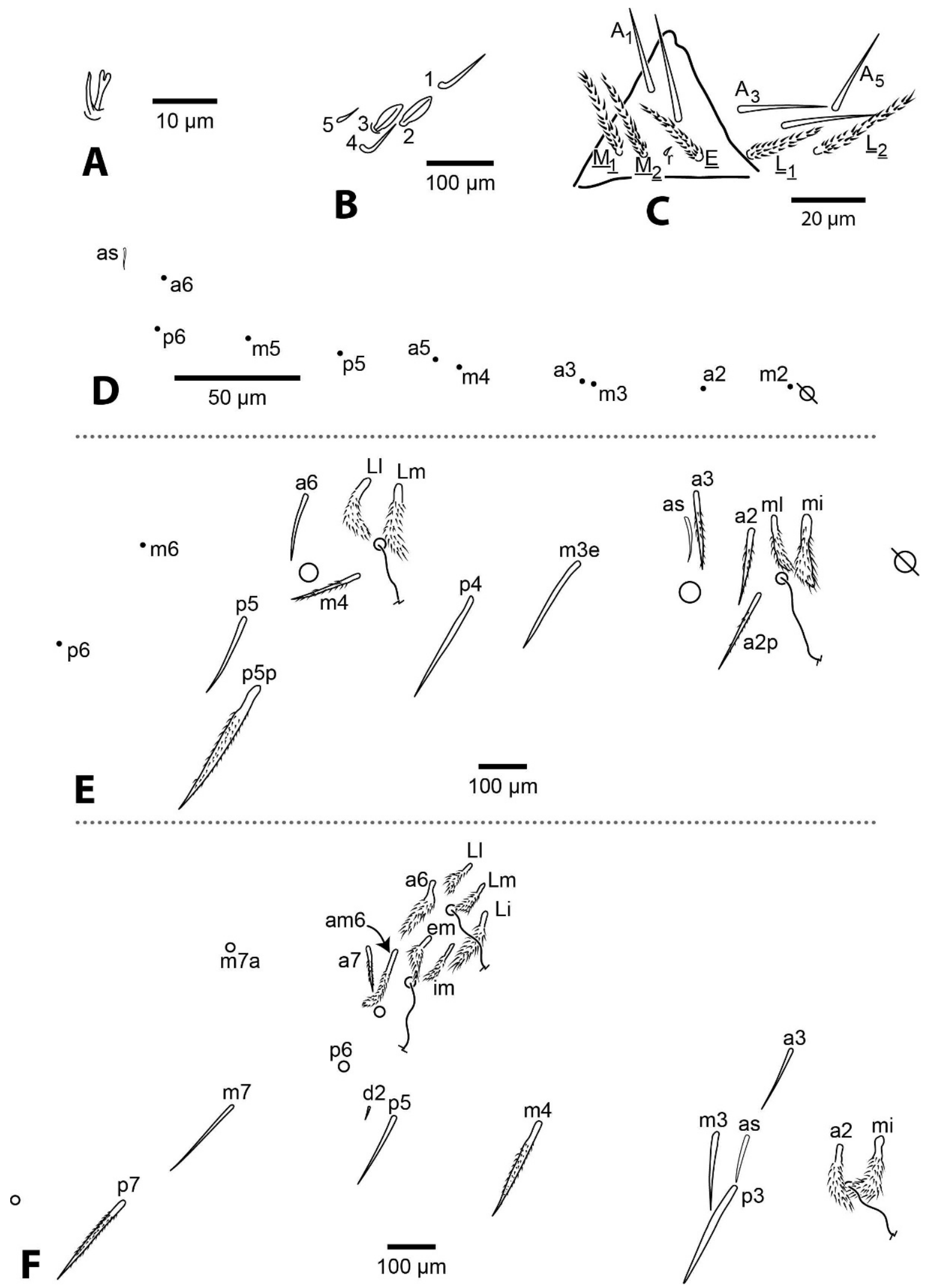

$Q$

Figure 8. Pseudosinella aera: (A) supapical organ of fourth antennal segment; (B) sense organ of third antennal segment and associated sensilla; (C) labial triangle. Tergal chaetotaxy, dots, open circles and crossed circles represent micro- and macrosetae and pseudopores, respectively; (D) abdomen 1; (E) abdomen 2; (F) abdomen 3. 

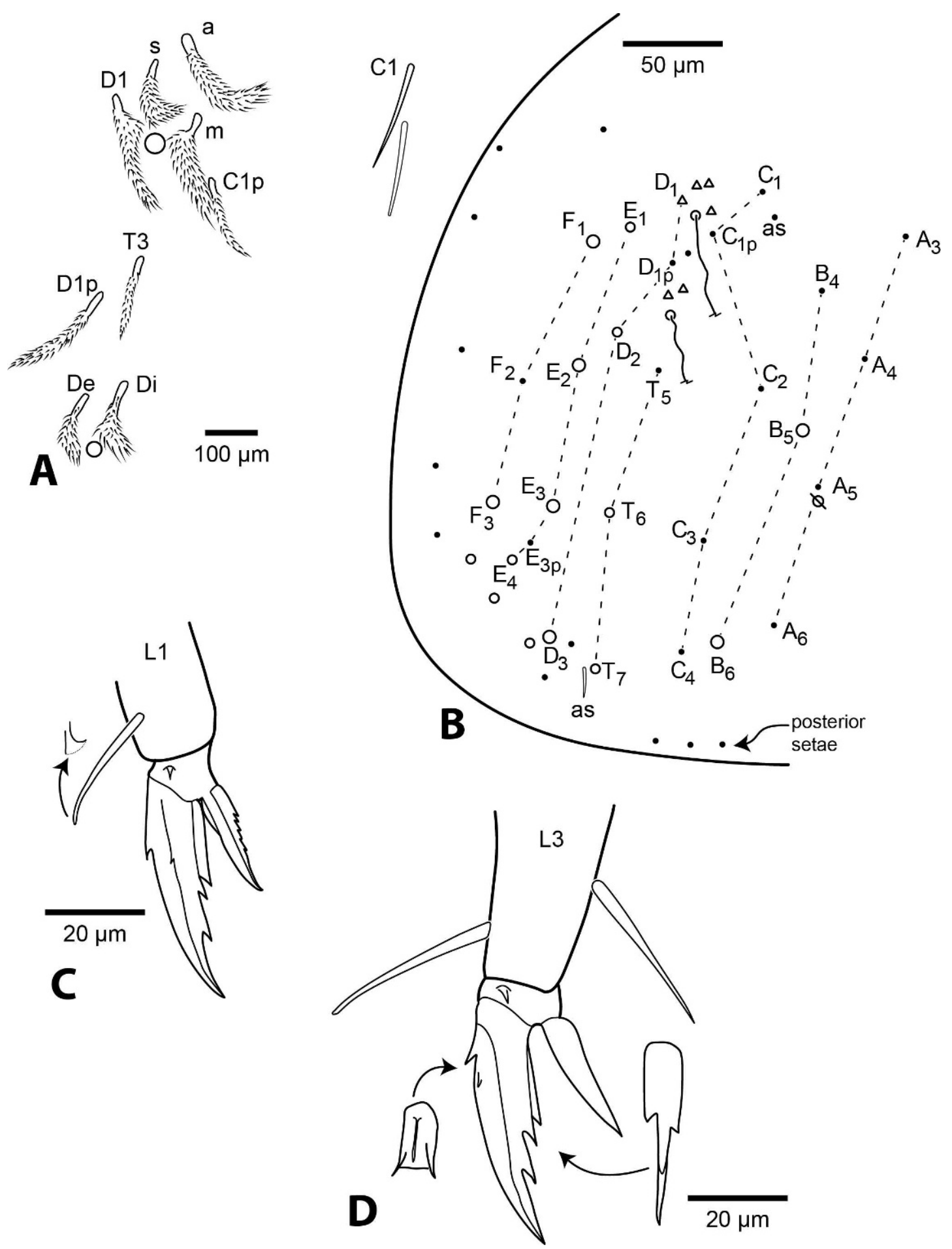

Figure 9. Pseudosinella aera, dots, open circles, triangles and crossed circles represent micro- and macrosetae, fan-shaped setae, and pseudopores, respectively: (A) abdomen 4 bothriotrichal complex; (B) complete chaetotaxy of abdomen 4; (C) prothoracic claw complex; (D) metathoracic claw complex.

setae in females, 15 in the single adult male studied, and 4 in one small juvenile. Internal face of all femora with 5 conic setae. All tibiotarsi with one posterior blunt or acuminate macroseta inserted near basal third of segment. Tenent hair weakly capitate, appearing acuminate or blunt at low magnification (Figs. 9C, D). Proportion of unguiculus: tenent hair: posterior smooth seta on hind legs as 1:1.3:1.3. Unguiculus lanceolate, posterior lamella serrate on forelegs, apparently smooth on hind legs. Unguis (Figs. 9C, D) with 4 internal teeth; basal teeth not aligned, 
one tooth slightly larger than other, basal tooth ending at $\approx 46 \%$ (range $43-49 \% ; n=3$ ) of inner claw length; distal unpaired tooth as large as basal teeth and ending at $\approx 74 \%$ (range 70-77\%; $n=3$ ) of inner claw length; external teeth conspicuous. Anterior face of ventral tube with 9 to 14 setae, 4 of them inserted along ventral groove, with 1 distal margin macroseta; lateral vesicles with 4 smooth and 5 to 10 strongly ciliate setae; distal margin of posterior face with 3 medial and 3 or 4 lateral setae, basal ventral chaetotaxy not clearly seen on any specimen, but apparently with 13 setae (5+5 and 3 unpaired). All manubrial setae ciliate; dorsal manubrial plate with 2 internal and 5 external, coarsely ciliate setae. Dens tubercle absent. Mucronal teeth subequal; mucronal spine with minute basal tooth.

Remarks: The individuals from Wizard Cave differ from the original description of the species only in having dorsal head macrosetae A3 present. Pseudosinella aera is very similar to $P$. argentea Folsom, $P$. flatua Christiansen and Bellinger, and $P$. granda Christiansen and Bellinger, but it is easily distinguished from all by the presence of $2+2$ eyes. In addition, it can be distinguished from $P$. flatua by the presence of ciliate prelabral setae, from $P$. argentea by the absence of seta m4i on Abd. 2, and from P. granda by the presence of only one head macroseta A0, by the presence of short acuminate labial seta $\mathrm{r}$, and by having a ciliate a3 on Abd. 2. Additional differences between the four species are listed in Table 2.

In Illinois Pseudosinella aera has been previously reported from caves in Gallatin and Johnson (Firestone Creek Cave) counties. P. aera appears to have a mostly southern distribution; the localities in Illinois are at or near the northernmost limit of the species. This species does not show strong adaptations to cave habitat, but almost all records, from Mexico to Illinois, are from caves.

\section{Pseudosinella argentea Folsom, 1902 - EU S2/G5? Localities: Spider Cave, Illinois Caverns}

As currently circumscribed, this species shows considerable morphological variation throughout its distribution, suggesting it likely represents a species complex (Christiansen and Bellinger, 1998). The specimens from the Salem Plateau have $4+4$ posterior setae on Abd. 4 (Fig. 10A), and the tenent hair on all legs is acuminate. This is consistent with the population of $P$. argentea reported from Maiden Cave, West Virginia (Soto-Adames, 2010).

This is a common cave species in Illinois. It has been previously reported from Caroll, Hardin (Brown's Hole Cave), and Monroe (Fults Saltpeter, Fogelpole, Spider and Wanda's Waterfall caves) counties. The species also appears to be common in caves in Kentucky, Missouri, Arkansas, Indiana, Alabama, Tennessee, Washington, Virginia, West Virginia, Pennsylvania, and Connecticut. Surface populations in Illinois have been reported from Champaign, Clark, Edgar, Johnson, and Union counties.
Coecobrya tenebricosa (Folsom), 1902 - EU S5/G5 (IN?) Localities: Wizard Cave, Pautler Cave, Wanda's Waterfall Cave, Illinois Caverns

This is a species commonly found in caves in North America. Previous reports from Illinois caves include Rose Hole and Pautler Cave, both in Monroe County.

This species was originally described from the Washington, D.C., area, but currently it is known to occur around the world in protected habitats such as greenhouses and caves (Chen and Christiansen, 1997). The genus Coecobrya is almost exclusively East Asian in distribution (Chen and Christiansen, 1997), and it is likely that $C$. tenebricosa represents an early introduction, during historic times, into North America.

\section{Entomobrya sp.}

Locality: Wizard Cave

The single individual collected is in an early instar and not identifiable to species.

\section{Homidia socia Börner, 1909 - TX IN \\ Locality: Spider Cave}

This is an introduced species. Almost all species of Homidia are restricted to East Asia and Oceania; only two (H. socia and H. sauteri) are known from North America. The oldest record of H. socia in North America appears to be from 1970, from Georgia (K. Christiansen, Collembola records database). The historical collection of springtails at the Illinois Natural History Survey that goes back to the second half of the 1800s, does not include representatives of this species, despite it now being the most common form found in grasses growing along country roads in Champaign County. Homidia socia was first noticed in a cave in Johnson County, southern Illinois, in 1973 (Christiansen and Bellinger, 1980, 1998; K. Christiansen, Collembola records database) and in Champaign County by the senior author in 1988. The species is also known from caves in Harrison and Crawford counties, Indiana.

\section{NeELIDAE}

Megalothorax minimus (Willem), 1900 - EU S5/G5

Locality: Wanda's Waterfall Cave

This is a common surface leaf litter species frequently found in caves. The species has been recorded from Grundy, Lawrence, and Washington counties in Illinois. This appears to be the first record for the species from Illinois caves.

\section{Megalothorax tristani (Denis), 1933 - TX S1/G1 Locality: Wizard Cave}

This is either a rare species or it has been generally confused with the more widely distributed $M$. incertus. Megalothorax tristani was previously reported from Illinois by Bonet (1948).

Neelides minutus (Folsom), 1901 - EU S5/G5

Locality: Wanda's Waterfall Cave

This is a common surface leaf litter species often seen in cave samples. In Illinois the species has been previously 


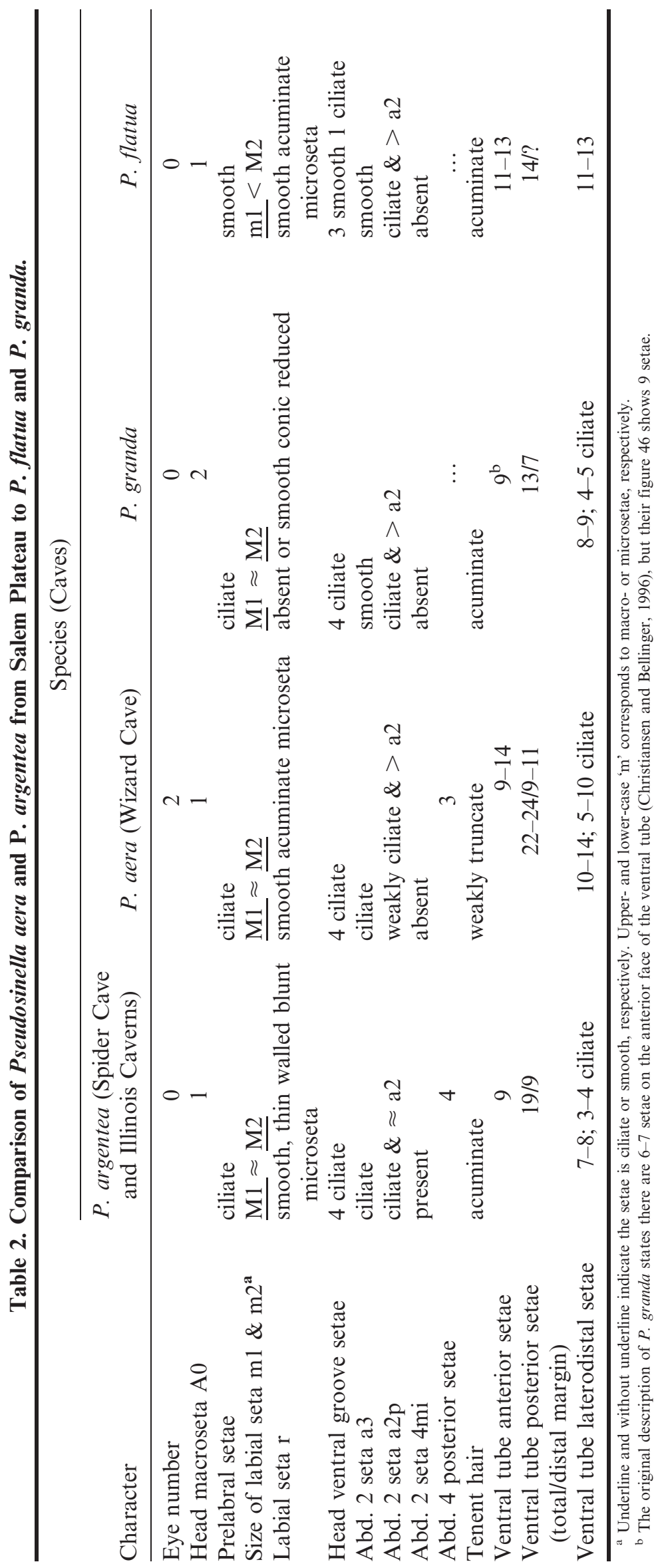



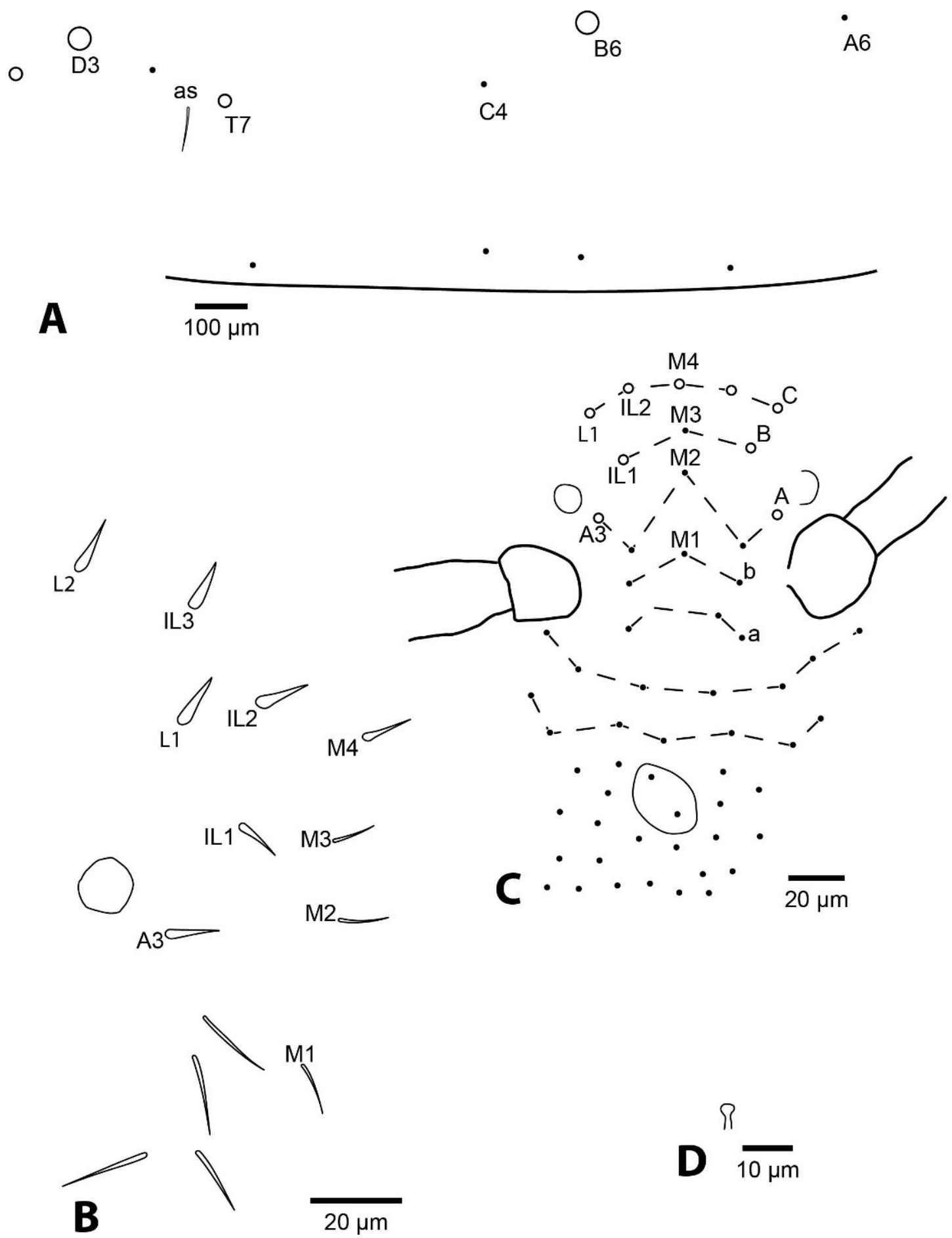

Figure 10. Pseudosinella argentea, dots, and open circles represent micro- and macrosetae, respectively: (A) posterior chaetotaxy of abdomen 4. Pygmarrhopalites fransjanssens n. sp., dots, and open circles represent microsetae and spine-like setae, respectively: (B) detail of vertical chaetotaxy of the head, left side; (C) general chaetotaxy of face; (D) subapical sensilla of fourth antennal segment.

reported from Calhoun, Cook, Gallatin, Jackson, Lake, La Salle, Lawrence, and Wayne counties.

\section{SMINTHURIDIDAE}

Sphaeridia serrata (Folsom and Mills), 1938 - TX S1/G3 Locality: Wanda's Waterfall Cave
This is an uncommon species previously reported from Herod and Pope counties in Illinois. This is the first record of this species from Illinois caves.

Sminthurides sp. - TX S1/G1

Locality: Bat Sump Cave

Journal of Cave and Karst Studies, August 2013•163 
This species has a unique combination of characters not seen in other Nearctic species. This is not a cave-adapted form. One male and one female were seen, and formal description of the species must await the study of further material.

\section{Arrhopalitidae}

Pygmarrhopalites fransjanssens $\mathrm{n}$. sp. - TB/EU? S1/G1?

Material Examined: Holotype, INHS Collection Number 551,634; USA, IL, St. Clair Co., Wizard Cave, Dupo, near Falling Spring, adult female, slide-mounted, collected in pitfall trap in twilight zone, 15-17 June 2009, SJ Taylor, FN Soto-Adames and CA Phillips. Paratypes, INHS Collection Number 551,635-36; 2 slide-mounted adult females on individual slides and 8 other individuals of undetermined sex in alcohol with same collection locality as holotype; 2 paratypes of undetermined sex collected with an aspirator under rotting log in twilight zone; 8 paratypes collected in pitfall traps in both dark and twilight zones.

Etymology: This species is dedicated to Frans Janssens, Department of Biology, University of Antwerp, Antwerp, Belgium, in recognition of his contributions to springtail taxonomy through the development of collembola.org.

Description: Largest individual $0.65 \mathrm{~mm}$. Background color white, with dark brown scattered over head, body, and all appendages. Ant. 4 with 5-6 subsegments in proportions as 26-32:10-11:10-11:10-11:10-11:27-29. Ant. 4 subapical sensilla capitate (Fig. 10D), each short preapical subsegment with 11 setae. Ant. 3 with a weak basal bulge (Fig. 11F); sense organ (Fig. 11G) with two rod sensilla in a shallow depression, setae Api and Ape appearing thin walled and with drawn out apices, but otherwise normally acuminate, Aai a rod sensilla. Eyes $1+1$ in a dark patch. Dorsal head chaetotaxy as in Figures $10 \mathrm{~B}$ and $\mathrm{C}$, with vertical setae M4, IL1-3, L1-2, and A3 short spine-like; M5 absent. Apical setae of outer maxillary lobe bifurcate, sublobular plate with three appendages (Fig. 11A). Labial palp papilla $\mathrm{E}$ with 3 guard setae. Latero-posterior setae (lp1) 2.5-3.5× seta c2 (Fig. 11B). Small abdomen without denticles or spines, chaetotaxy as in Figure 10C: C1 bifurcate, C2-6 and C8 smooth, enlarged at base but without tunica, $\mathrm{C} 7$ and $\mathrm{C} 9$ long but not basally enlarged; seta $\mathrm{C} 2 \approx 1.3 \times \mathrm{B} 2$ and $\mathrm{C} 3 \approx 2.2 \times \mathrm{D} 3$; setae D7-8 absent, D9 typically long; female appendage (Fig. 11D, E) palmate, with smooth stem and shallow branches, sitting on a circular papilla. Metatrochanter longer than it is wide (Fig. 12A), with 5 setae. All claws with 1 inner tooth (Figs. 12B, C); dorsal tunica smooth, covering distal half of L1-2, and 4/5 of L3. Unguiculus of all legs with inner tooth, outstanding on L1 but so minute on L3 as to be visible only in some perspectives; apical unguicular filament surpassing length of unguis on all legs. Tenaculum with 2 setae. Manubrium with $4+4$ dorsal setae. Dens dorsally (Fig. 12D) with 3 inner (L), 6 dorsal (D1-2, ID1-4) and 7 external (E) setae; setae L1-3, E1 and E3 spine-like. Dens ventrally with 2 unpaired setae. Mucro with spatulate apex.

Remarks: This species is characterized by the combined presence of 3 sublobal setae on the maxillary palp, $4+4$ dorsal manubrial setae, a palmate female appendage, and small abdomen with setae $\mathrm{C} 1$ bifurcate and setae D7-8 absent. Table 3 lists varying characters for the group of species with palmate female appendage, small abdomen seta $\mathrm{C} 1$ bifurcate, and two unpaired ventral seta on dens. Pygmarrhopalites fransjanssens $\mathrm{n}$. $\mathrm{sp}$. is most similar to $P$. incantator $\mathrm{n}$. sp., from which it differs in the number of sublobal setae on the maxillary palp, the number of guard setae on labial papilla $\mathrm{E}$, the number of dorsal manubrial setae, the absence of D7-8 on the small abdomen, and the shape of metathoracic unguiculus.

The new species keys out to $P$. principalis (Stach) in Bretfeld (1999), but the differences between the two forms are not clear because the state of some characters in the European form remain in dispute. Stach's (1945) original description of $A$. principalis does not mention the condition of small abdomen seta C1. Vargovitsh (2009) points out that Gisin's (1947) Figure 2 shows C1 as bifurcate, the mucro as pointed instead of spoon shaped, and the small abdomen setae in series $\mathrm{C}$ as basally expanded instead of enlarged but simple. In addition, Gisin (1947) depicts head vertical setae A3, IL 1-2, and L1 as strongly spine-like and distinct from those in series $\mathrm{M}$, and seta M4 is absent. Fjellberg (1984) first reported $P$. principalis from North America, but the condition of $\mathrm{C} 1$ is not mentioned, and his Figure 9C shows what appears to be vertical head seta M5 present and M4 absent. Fjellberg (2007) reported that Fennoscandian populations of $A$. principalis have vertical cephalic M1-3, but not M4-5, maxillary palp with two sublobal hairs, and labial palp papilla E with 3 guard setae. Fjellberg (2007) does not mention the number of manubrial setae or the condition of C1. Vargovitsh (2009) described a new subspecies, $P$. principalis skelicus, which he diagnosed based on the relative length of antennae to cephalic diagonal and the presence of annulations on Ant. 4 of males. Vargovitsh (2009) presented the most complete description for $P$. principalis so far published, but he does not mention the number of setae on the maxillary palp or labial papilla $\mathrm{E}$. In view of the differences between $P$. fransjanssens n. sp., $P$. principalis skelicus, and $P$. principalis in the sense of Gisin (1947) and Fjellberg (2007), we opted to describe the form collected at Wizard Cave as a new species.

\section{Pygmarrhopalites incantator n. sp. - EU/TB? S1/G1}

Material Examined: Holotype: INHS Collection Number: 551,638; USA, IL, St. Clair Co., Wizard Cave, Dupo, near Falling Spring, adult female, slide-mounted, collected in pitfall trap in twilight zone, 15-17 June 2009, SJ Taylor, FN Soto-Adames and CA Phillips. Paratypes, INHS Collection Number 551,639-40; 1 adult female and 1 adult 

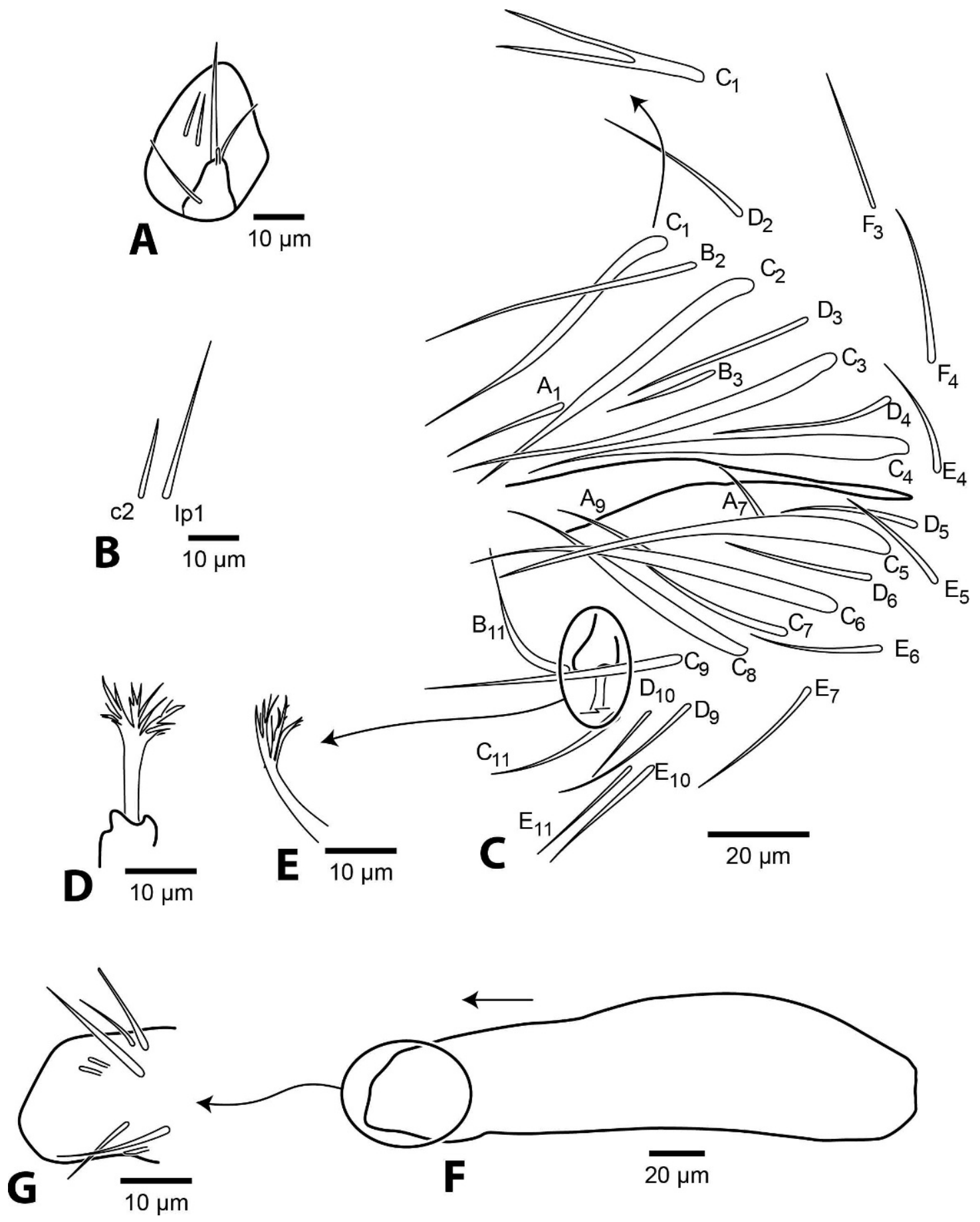

Figure 11. Pygmarrhopalites fransjanssens $\mathrm{n}$. sp.: (A) dorsal view of outer maxillary palp and lobe; (B) big abdomen setae c2 and Ip1; (C) lateral view of complete chaetotaxy of female anal valves, inset dorsal view of seta $\mathrm{C} 1$ from another individual; (D) dorsal view of female anal appendage; (E) lateral view of female anal appendage; (F) third antennal segment; (G) detail of apical sense organ of third antennal segment.

male mounted on individual slides with same collection information as holotype.

Etymology: The epithet of the new species refers to Wizard Cave, the type locality.

Description: Largest individual $1.0 \mathrm{~mm}$. Background color white, with orange spots scattered over head, body, and all appendages. Ant. 4 with 6 subsegments (Fig. 12E) in proportions as 36-37:11:10:10:10:25. Ant. 4 subapical sensilla capitate as in $P$. fransjanssens $\mathrm{n}$. sp., each short sub terminal subsegment with 11 setae. Ant. 3 without basal bulge (Fig. 12F); sense organ as in P. fransjanssens n. sp., with 2 rod sensilla in independent shallow depressions, 

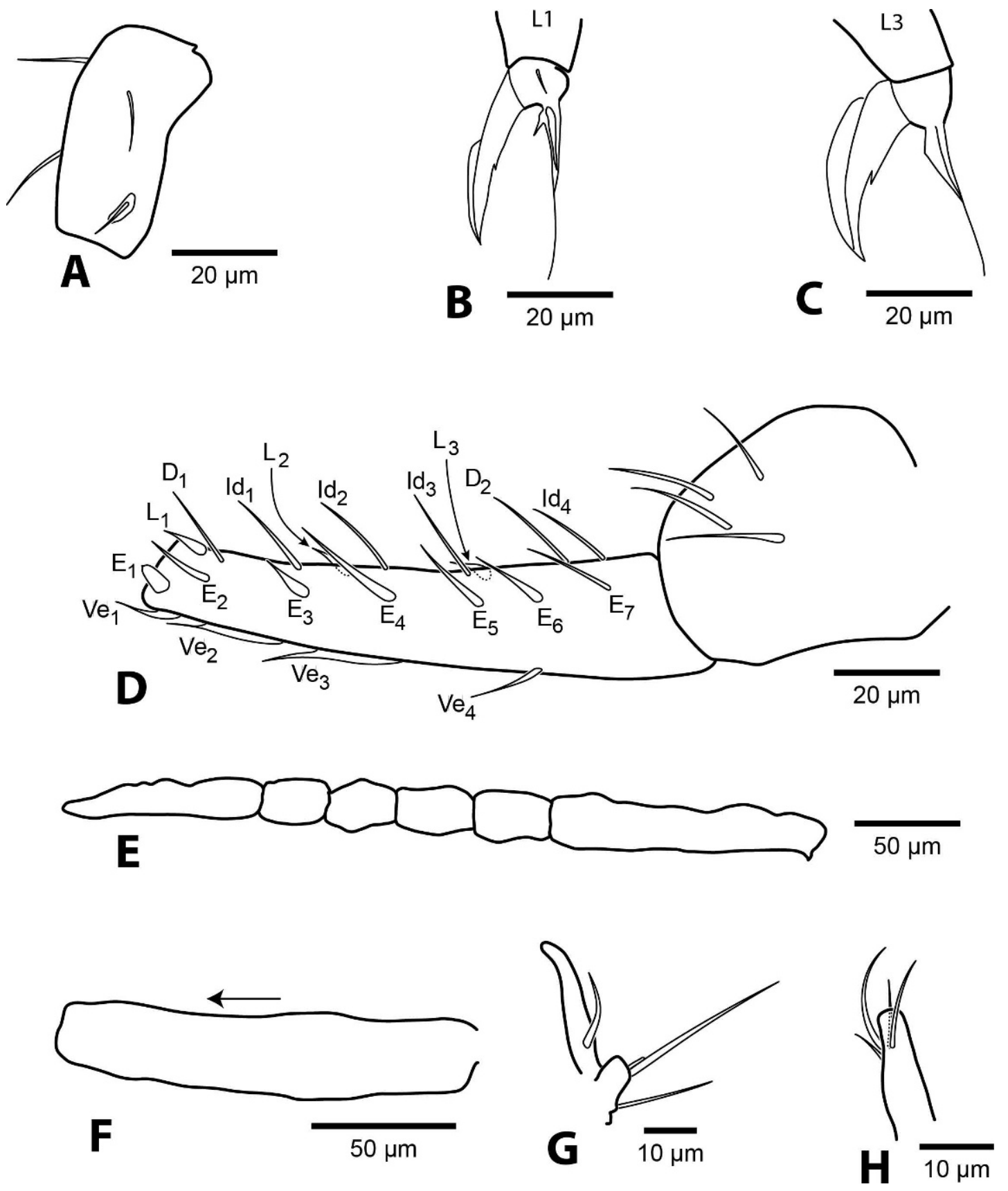

Figure 12. Pygmarrhopalites fransjanssens n. sp.: (A) metatrochanter; (B, C) pro- and metathoracic claw complexes, respectively; (D) complete chaetotaxy of furcula, $\mathrm{L}=$ inner column, $\mathrm{D}=$ dorsal, $\mathbf{l d}=$ laterodorsal, $\mathrm{E}=$ outer column. Pygmarrhopalites incantator n. sp.: (E) fourth antennal segment; (F) third antennal segment; (G) lateral view of outer maxillary palp and lobe; $(\mathrm{H})$ ventral view of labial palp papilla $\mathrm{E}$, terminal seta omitted.

setae Api and Ape appearing thin walled and with drawn out apices, but otherwise normally acuminate, Aai a rod sensilla. Eyes $1+1$ in a dark patch. Dorsal head chaetotaxy (Figs. 13A, B) with setae A3, IL1, M4, and L1-3 weakly spine-like; M5 absent. Apical setae of outer maxillary lobe bifurcate (Fig. 12G), but basal spine closely appressed against apical setae and visible only in some perspectives; sublobular plate with one appendage. Labial palp papilla E with 4 guard setae (Fig. 12H). Small abdomen without denticles or spines; chaetotaxy as in Figure 13C: C1 bifurcate, C2-6 smooth, enlarged at base but without extensions, base of C7-8 not enlarged; seta $\mathrm{C} 2 \approx 1.2 \times \mathrm{B} 2$ and $\mathrm{C} 3 \approx 1.7 \times \mathrm{D} 3$; setae D7-D8 present; female appendage (Fig. 13D) palmate, with smooth stem and deep branches, some of which originate close to the middle of the stem, appendage sitting on a circular papilla. Metatrochanter rectangular, with 4 anterior and 1 posterior setae. All claws with 1 inner tooth (Figs.13E, F), tooth strongest on L3; 


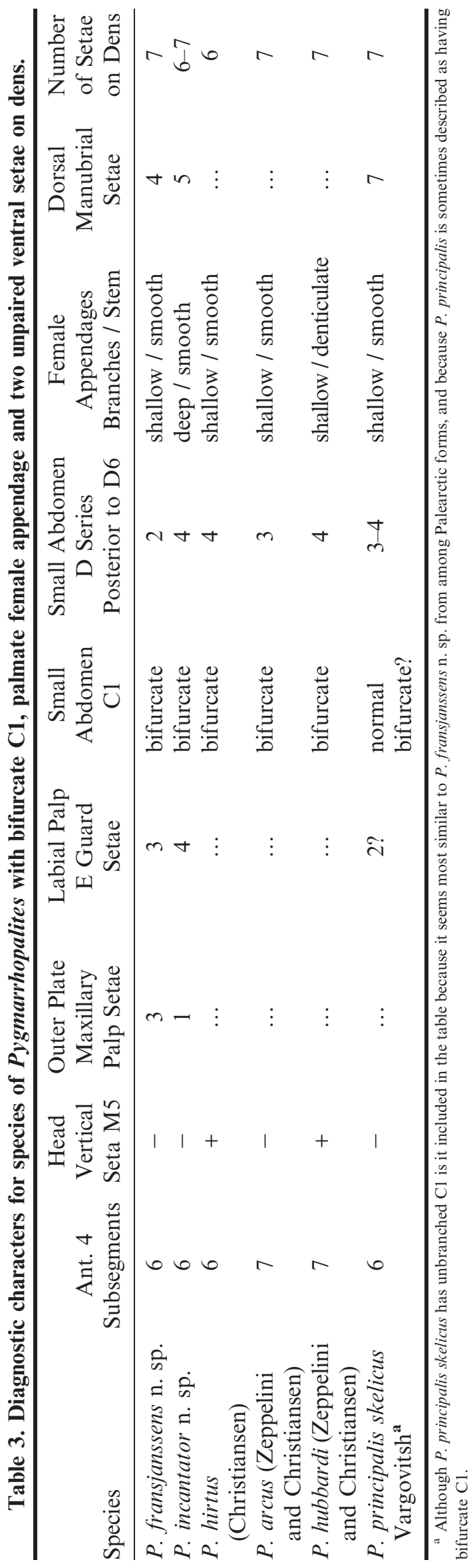

dorsal tunica on all legs smooth, covering apical third of claw on L1-2 and 4/5 of L3 claw. Unguiculus of L1 with a minute inner tooth, unguiculus of L2 -3 toothless, apical unguicular filament surpassing length of unguis on all legs. Tenaculum with 2 setae. Manubrium with $5+5$ dorsal setae. Dens dorsally (Fig. 14A) with 3 inner (L) and 6 dorsal (D12 , ld1-4) setae; series E with a maximum of 7 setae in females and 6 in male; setae L1-3, E1, and E3 spine-like. Dens ventrally with 2 unpaired setae. Mucro with spatulate apex.

Remarks: Both females have one dens with $7 \mathrm{E}$ setae and one with 6 setae. In both cases the missing seta is E6. In one female, the dens without E6 also has only 5 dorsal setae.

This species is distinguished from $P$. hirtus as described by Christiansen and Bellinger (1998) and Zeppelini and Christiansen (2003) by the absence of head vertical seta M5, by the shape of the female appendage and, perhaps, by the presence of a smooth tunica on all claws. One individual from Wisconsin deposited at the INHS and identified as $P$. hirtus (Zeppelini et al., 2009) is identical to the specimens from Wizard cave in having only four vertical head setae in series M (M5 absent), the number of dorsal manubrial setae, general shape of female appendage, and the number of maxillary and labial palps setae.

Pygmarrhopalites sapo (Zeppelini and Christiansen), 2003 - TB S1/G1

Locality: Pautler Cave

The individuals studied have $6+6$ dorsal manubrial setae, maxillary palp with bifurcate apical seta and 3 sublobal appendages, and labial papilla $\mathrm{E}$ with 3 guard setae.

This species is endemic to Monroe County, and it previously was reported from Frog, Pautler, Jacobs, and Rose Hole caves (Zeppelini and Christiansen, 2003).

Pygmarrhopalites salemensis n. sp. - TB S1/G1

Material Examined: Holotype: INHS Collection Number 551,641; Illinois, St. Clair Co, Stemler Cave, $2.7 \mathrm{mi} \mathrm{NE}$ of Columbia IL, adult female, slide-mounted, hand collected on cave floor in dark zone, 28-30 September 2009, SJ Taylor and FN Soto-Adames. Paratypes on slides with INHS Collection Numbers 551,642-50; same locality as holotype, 1 slide-mounted adult female and 3 adults of undetermined sex in alcohol, hand collected on drip pool, dark zone; Illinois, Monroe Co., Wanda's Waterfall Cave, $7.4 \mathrm{mi}$ SE of Valmeyer, 2 females and 1 male adults on individual slides and 1 adult of undetermined sex in alcohol collected in pitfall traps and by hand on cave floor 15-17 September 2009, SJ Taylor and FN Soto-Adames; Illinois, Monroe Co., Illinois Caverns, 1 adult female mounted on a slide, pitfall trap in dark zone, 2 additional adults and 1 juvenile of undetermined sex in alcohol, pitfall and leaf litter, 24-26 September 2009, SJ Taylor, FN Soto-Adames, A Kuhns, E Zaborski, J Jacoby, A Paprocki, and M Pessino; Illinois, Monroe Co., Spider Cave, $6.5 \mathrm{mi} \mathrm{S}$ of Waterloo, 1 slide-mounted adult male, pitfall trap, 15-17 September 2009, SJ Taylor and FN Soto-Adames; Illinois, 

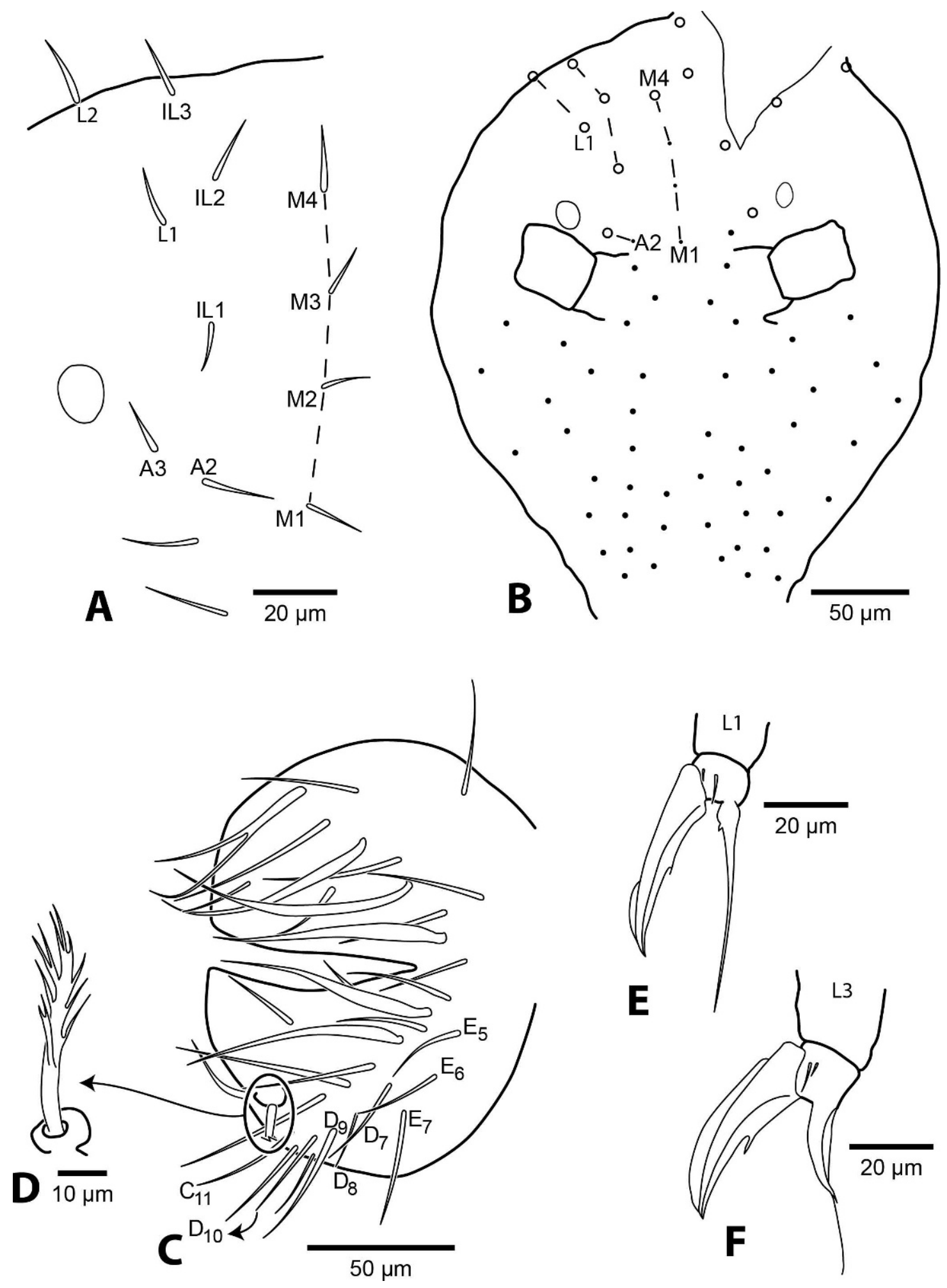

Figure 13. Pygmarrhopalites incantator n. sp., dots, and open circles represent microsetae, and spine-like setae, respectively: (A) detail of vertical setae of the head; (B) general chaetotaxy of face (C) complete chaetotaxy of small abdomen, lateral view; (D) female anal appendage; (E, F) pro- and metathoraxic claw complex, respectively. 


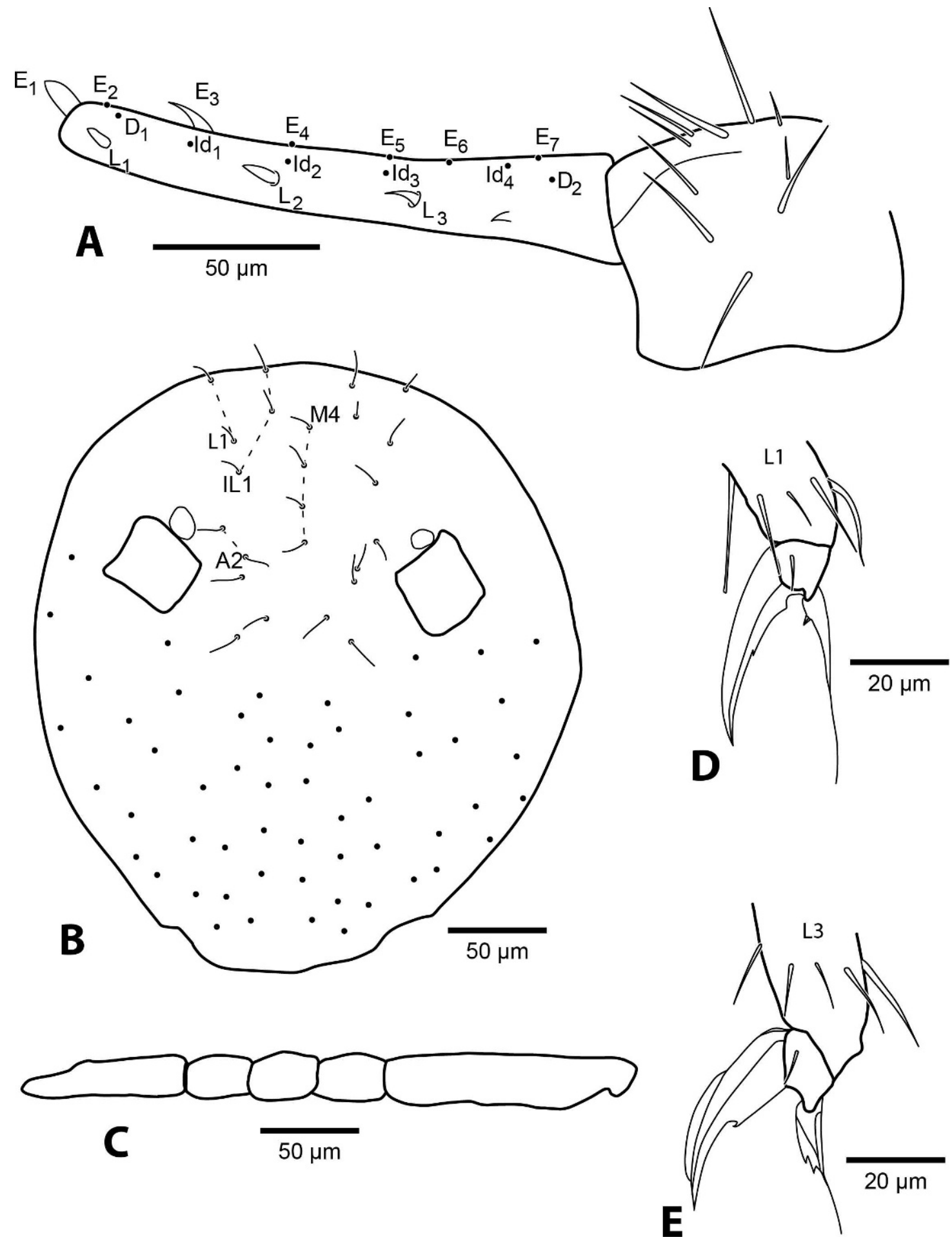

Figure 14. Pygmarrhopalites spp., dots represent regular acuminate setae: Pygmarrhopalites incantator n. sp.: (A) complete dorsal chaetotaxy of furcula, $\mathrm{L}=$ inner column, $\mathrm{D}=$ dorsal, $\mathrm{Id}=$ laterodorsal, $\mathrm{E}=$ outer column. Pygmarrhopalites salemensis n. sp.: (B) complete chaetotaxy of face; (C) fourth antennal segment; (D, E) pro- and metathoraxic claw complex, respectively.

Monroe Co., Hidden Hand Cave, $3 \mathrm{mi}$ W of Waterloo, 2 adult females and 1 juvenile, slide-mounted, 7 additional adults and juveniles in alcohol, pitfall traps in dark zone, 14-16 October 2009, SJ Taylor and FN Soto-Adames.
Etymology: The new species is named after the Salem Plateau region, where it seems to be widespread in caves.

Description: Largest individual $0.89 \mathrm{~mm}$. Background color white, with dark orange spots on head covering 


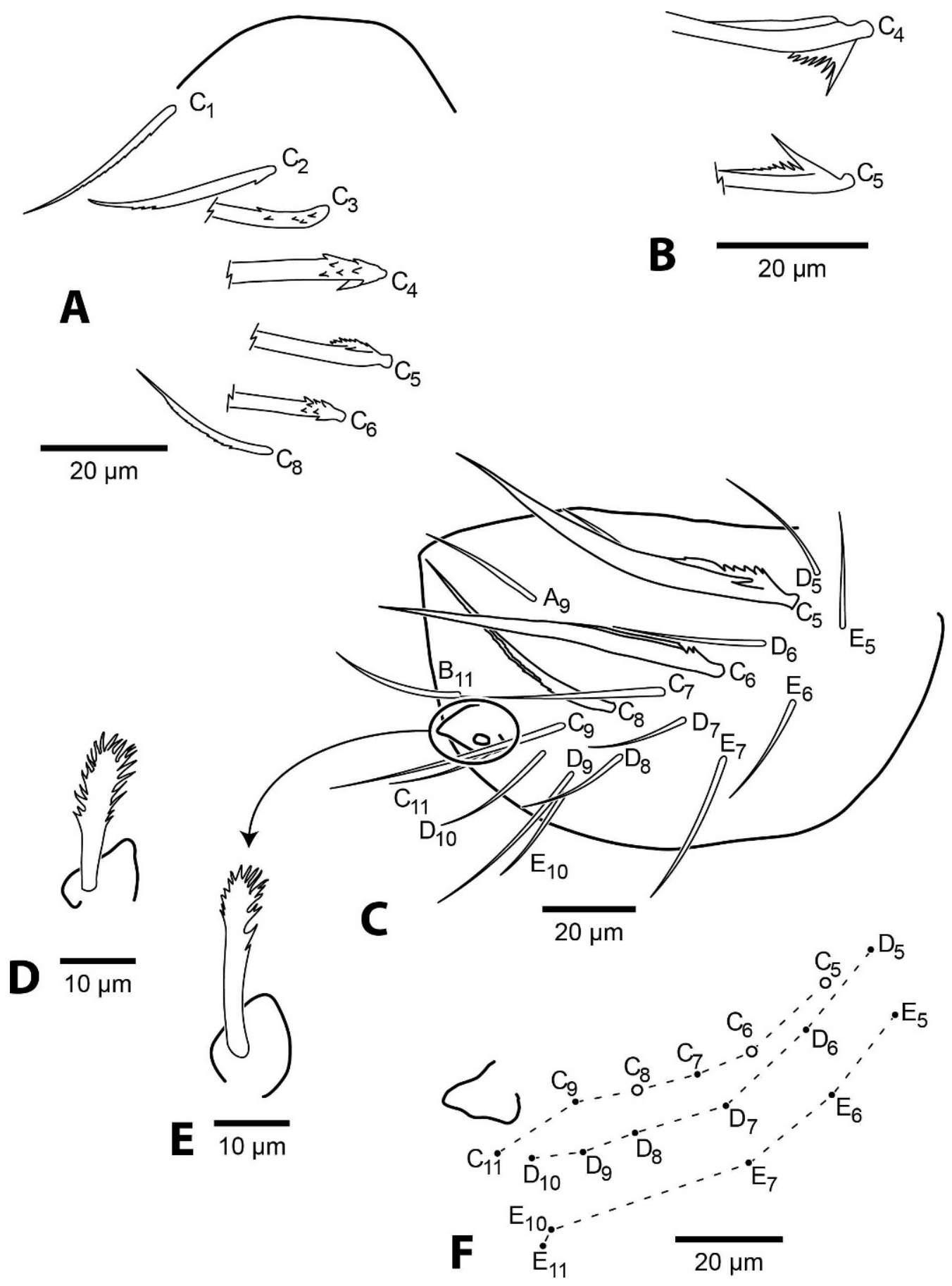

Figure 15. Pygmarrhopalites salemensis n. sp., chaetotaxy of female small abdomen, dots and open circles represent microand macrosetae, respectively: (A) series $C$ setae of holotype, Stemler Cave; (B) setae $C_{4}$ and $C_{5}$, female paratype from Stemler Cave; (C) complete chaetotaxy of lower valve, paratype from Spider Cave; (D, E) detail of female anal appendage, paratypes from Wanda's Water Fall and Stemler Cave, respectively; (F) organization of complete chaetotaxy of lower valve in holotype.

clypeus, area between antennal bases and vertex; genal and labral areas white; large abdomen with scattered orange spots dorsolaterally, sometimes forming ill defined stripes; small abdomen and all appendages white. Ant. 4 with 5 subsegments (Fig. 14C) with proportions as 40:10:10:10:30 of the total Ant. 4 length. Ant. 4 with 4 well defined whorls of setae corresponding to the apical whorl on subsegment I and each one of subsegments II-IV; the number of setae/ sensilla on each whorl as 10/10/12/12; basal whorls missing 2 sensilla present on distal whorls. Ant. 4 subapical sensilla capitate. Ant. 3 without basal bulge; sense organ with two rod sensilla in independent shallow depressions, setae Api 

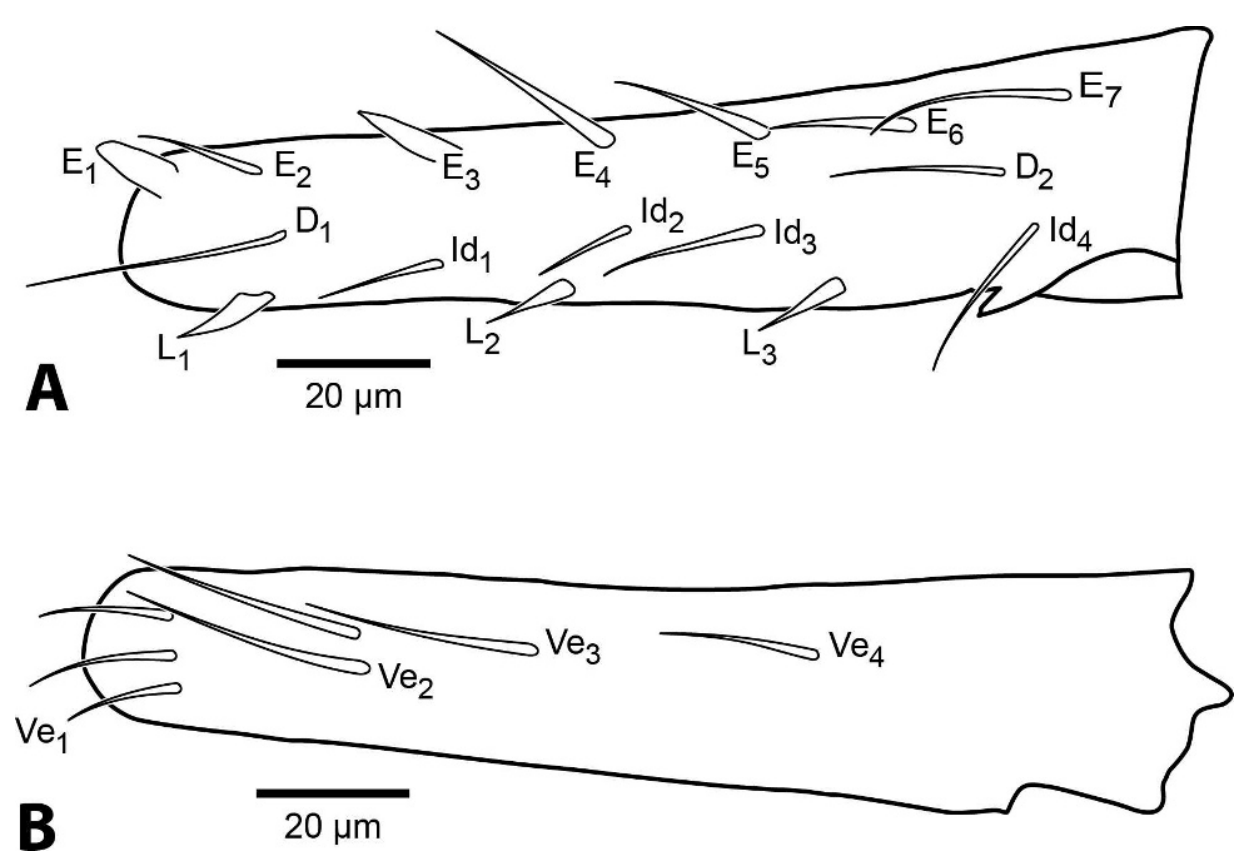

Figure 16. Pygmarrhopalites salemensis $n$. sp., complete dorsal chaetotaxy of dens: (A) dorsal, $\mathrm{L}=$ inner column, $\mathrm{D}=\mathrm{dorsal}$, ld = laterodorsal, $\mathrm{E}=$ outer column; (B) ventral.

and Ape appearing thin walled, basally swollen and with drawn out apices, but otherwise normally acuminate, Aai a rod sensilla. Eyes $1+1$ in dark orange patch. All vertical head setae normal (Fig. 14B), M5 absent. Apical setae of outer maxillary lobe bifurcate; sublobular plate with three hairs. Labial papilla $\mathrm{E}$ with 4 guard setae. Small abdomen without denticles or spines, chaetotaxy of series $\mathrm{C}$ as in Fig. 15A: C1 simple and smooth or very finely serrate; $\mathrm{C} 2$ 6 and $\mathrm{C} 8$ with basal serrations, denticles or teeth, and lateral extensions variously developed according to individuals and localities (Figs. 15B, C); setae C7 and C9 long but not basally enlarged; seta $\mathrm{D} 2 / \mathrm{F} 3=1.2$ to 1.8 $($ mode $=1.6 ; 3 / 7) \mathrm{C} 2 / \mathrm{B} 2=0.9$ to $1.1(\operatorname{mode}=1.1 ; 5 / 7)$ and $\mathrm{C} 3 / \mathrm{D} 3=1.8-3.1 \quad($ mode $=2.0 ; 2 / 7)$; setae $\mathrm{D} 7-10$ present (Figs. 15C, F); female appendage apically square or rounded (Figs. 15D, E), with short serrations covering apical $1 / 3-2 / 3$ and sitting on a heart-shaped papilla. Metatrochanter rectangular, with 4 anterior and 1 posterior setae. All claws with 1 inner tooth. Unguiculus with inner tooth large, single and basal on L1 and L2 (Fig. 14D), and absent or small, duplicated, and distal on L3 (Fig. 14E); apical unguicular filament acuminate and surpassing length of unguis on all legs. Tenaculum with 2 setae. Manubrium with $6+6$ dorsal setae. Dens dorsally (Fig. 16A) with 3 inner (L), 6 dorsal (D1-2, 1d1-4) and 7 external (E) setae; setae L1-3, E1 and E3 spine-like. Dens ventrally (Fig. 16B) with 2 unpaired setae. Mucro apically acuminate and $0.6-0.7 \times(\operatorname{mode}=0.7 ; 4 / 7)$ as long as dens.

Remarks: One individual from Wanda's Waterfall Cave has 10/11/11/11 setae/sensilla on whorls I-IV. The two individuals from Stemler Cave are missing dental seta E6 on one dens but not the other. One individual from Stemler Cave has one proximal and one distal inner unguicular tooth on L1-2, but only the distal tooth on L3. One individual from Hidden Hand Cave has 3 tenacular setae.

Pygmarrhopalites salemensis $\mathrm{n}$. $\mathrm{sp}$., belongs to a group of Midwestern species characterized by having five subsegments on Ant. 4 and small abdomen series $C$ setae sculptured or with lateral extensions. The five species in the group differ in details of the sculpturing of setae in series $\mathrm{C}$, shape of the female appendage, number of dental spines, number of ventral unpaired setae on dens, and number of head vertical setae in series $M$ (Table 4). The new species seems intermediate between the recently described $P$. sapo and $P$. leonardwoodensis Zeppelini, Taylor and Slay, 2009. The three species can be distinguished by dens chaetotaxy, pattern of sculpturing of small abdomen setae C3-6, and female appendage according to Table 4 . In addition, in $P$. leonardwoodensis the inner tooth on the prothoracic claws is basal, while in $P$. salemensis the tooth is insert near the middle of the claw; $P$. sapo carries 3 guard setae in labial papilla E, whereas $P$. salemensis has 4 guard setae. Differences with other species are detailed in Table 4.

\section{KATIANNIDAE}

Sminthurinus henshawi (Folsom), 1896 - EU S5/G5

Locality: Bat Sump Cave

This is a common surface species widespread across North America. In Illinois, the species has been previously reported from Jackson, Champaign, Coles, Cook, DuPage, Kane, Lake, Randolph, Richland, and Woodford counties. 


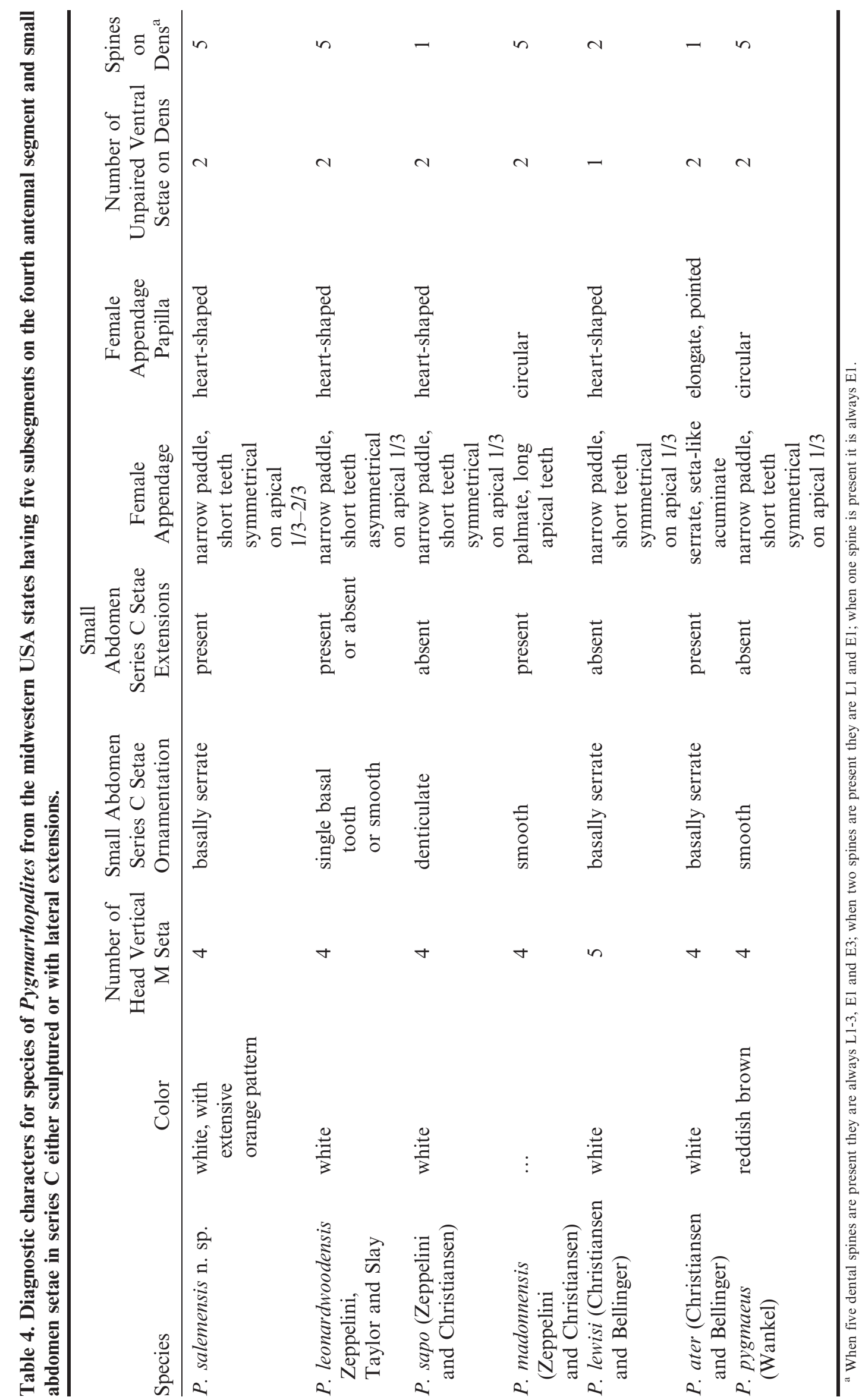


F.N. Soto-Adames And S.J. TAYlor

Table 5. Comparison of springtail species recorded from caves in the Salem Plateau (Monroe and St. Clair counties, Illinois) by Lewis et al. (2003) relative to the number recorded in the present study.

\begin{tabular}{lcccc}
\hline Cave & $\begin{array}{c}\text { Lewis } \\
\text { et al. (2003) }\end{array}$ & $\begin{array}{c}\text { Present } \\
\text { Study }\end{array}$ & $\begin{array}{c}\text { Species in } \\
\text { Common }\end{array}$ & $\begin{array}{c}\text { Lewis et al. (2003) Species } \\
\text { not Found in Present Study }\end{array}$ \\
\hline Pautler Cave & 2 & 4 & 2 & 0 \\
Wanda's Waterfall Cave & 1 & 22 & 0 & Pseudosinella sp. nr. argentea \\
Spider Cave & 1 & 7 & 1 & 0 \\
Stemler Cave & 1 & 15 & 1 & 0 \\
Illinois Caverns & 3 & 13 & 2 & Lethemurus missus \\
Hidden Hand Cave & 3 & 4 & 1 & $\begin{array}{c}\text { Pygmarrhopalites carolinae } \\
\text { Onychiurus "reluctus" }\end{array}$ \\
Bat Sump Cave & 2 & 12 & 1 & Sensilanura illina \\
Total & 13 & 77 & 8 & 5 \\
\hline
\end{tabular}

Sminthurinus henshawi is common in caves, but this is the first record from this habitat in Illinois.

\section{BOURLETIELLIDAE}

Bourletiella sp.

Locality: Spider Cave

This is an early instar individual not identifiable to species. Members of this genus are not commonly found in caves. This is likely an accidental.

\section{Dicyrtomidae}

Ptenothrix sp.

Locality: Spider Cave

The single juvenile collected is not identifiable to species. Several species of Ptenothrix frequent caves, including $P$. atra, $P$. marmorata, and $P$. maculosa. In Illinois, $P$. atra is the species most commonly reported from caves.

\section{Discussion}

Sampling of eight caves in the Salem Plateau region using a combination of methods yielded forty-nine species, sixteen of which represent new records for Illinois. The new records include four species described as new, four species that are likely new, but with insufficient material for proper descriptions, and three other forms that were assigned names but are sufficiently distinct that a study of additional material may show them to also represent new species. Eighteen species are reported for the first time from Illinois caves. Seventeen species are ranked as rare for the state (S1), but eight of these are widely distributed across North America and the state ranking is either an artifact of the relatively poor knowledge of the fauna of the state or the result of unresolved taxonomic issues (e.g., Onychiurus pipistrellae $\mathrm{n} . \mathrm{sp}$.). Some of the other species ranked as rare are probably truly rare in the state, even if they are widespread elsewhere on the continent, because they represent the limit of the distributional range for the species (e.g., Pseudosinella aera, Folsomia bisetosa, Proisotoma sepulcralis, and Megalothorax tristani). Others, such as Pygmarrhopalites spp., are probably truly rare and endemic to the region.

Twelve species have morphological characters that suggest some level of adaptation to caves and are classified as either troglobionts, or eu- or subtroglophiles. Seven species (Ceratophysella lucifuga, Onychiurus pipistrellae n. sp., Lethemurus missus, Pygmarrhopalites fransjanssnes n. sp., $P$. incantator n. sp., $P$. sapo, and $P$. salemensis n. sp.) are currently known only from caves, although $L$. missus and perhaps $O$. pipistrellae n. sp. are widely distributed across unconnected cave systems, suggesting they are able to migrate through protected surface habitats. Most collections of Oncopodura iowae have been made in caves, but recent surface collections in cave bearing areas suggest a mechanism to explain its widespread distribution. It is possible that similar mechanisms may support the movement and dispersal of L. missus and $O$. pipistrellae n. sp. through surface leaf litter. Folsomia candida, F. stella, Pseudosinella argentea, P. aera, and Coecobrya tenebricosa show weak morphological adaptations to caves, all are widely distributed across North America and surface populations are not rare.

Seven of the caves surveyed were previously sampled by Lewis et al. (2003). They published findings relating primarily to troglobionts, whereas the present study reports on findings for springtails of all ecological classifications found in caves. In addition, our study focused only on springtails, whereas Lewis et al. (2003) surveyed all cave invertebrates. In all instances each cave sampled in the present survey yielded more springtail species than reported by Lewis et al. (2003) (Table 5). Most species reported by Lewis et al. (2003) were collected again during the present survey. Five records listed by Lewis et al. (2003) were not confirmed by the present study (Table 5). The absences of collections of Pseudosinella from Wanda's Waterfall Cave, of Pygmarrhopalites carolynae (Christiansen and Bellinger), of Onychiurus "reluctus" from Hidden Hand Cave, and of Sensillanura illina (Christiansen and Bellinger) from Bat Sump Cave during the present survey is curious, given that these were the 
shortest cave included in the present study and, with the exception of Wanda's Waterfall Cave, we sampled nearly the full length of the accessible passages at these sites. Pygmarrhopalites carolynae and P. salemsis n. sp., the only Pygmarrhopalites collected in Hidden Hand Cave, differ sharply in color pattern, small abdomen setae ornamentation and female anal appendage, and hind claw morphology, and it is not likely the two species could be confused. Sensillanura illina is probably a trogloxene or subtroglophile, and although the species was not collected inside Bat Sump Cave during our visits, it was taken in surface leaf litter sampled near the cave entrance on the same day the cave was visited.

The absence of Lethemurus missus in samples from Illinois Caverns is not surprising. Illinois Caverns is a large, complex system, and most areas of the system were not sampled during the present study due to time constraints. Sampling effort focused on those sections of the cave most impacted by the large number of visitors that tour this system every year; the cave has since been closed to the public in an attempt to help manage white nose syndrome of bats.

It is telling about the general state of our knowledge of the springtail fauna of Illinois that leaf litter samples collected inside caves at the entrance, have yielded three new species and six new state records of what are clearly surface leaf litter species.

It is of some concern that Coecobrya tenebricosa, the only member of the Sinella-Coecobrya genera complex, a complex of typically eu/subtroglophile or troglobiont species, is an invasive species. It is not clear what the role of this introduced springtail species might be in fragile cave ecosystems. Caves in the Shawnee Hills, south of the Salem Plateau region, harbor three native species of eutroglophiles/troglobionts in the genus Sinella (Christiansen and Bellinger, 1998). It is possible that the introduced form could move south, invade caves, and extirpate the native springtail species.

The relatively large number of new species and records for the state and the potential threat to native eutroglophiles and troglobionts by introduced species point to the need for continued detailed, taxon-focused sampling of cave systems in Illinois. Only through intense sampling will we be able to identify communities under threat and have the information needed to make more effective management and conservation decisions.

\section{ACKNOWLEDGEMENTS}

We thank all volunteers and scientists who helped with field work, including JoAnn Jacoby, Andy Kuhns, Annie Paprocki, Massimo Pessino, Chris Phillips, Bob Weck, and Ed Zaborski. We thank Lesley Deem for her valuable assistance in sorting material in the laboratory. We are grateful to all the landowners who provided access to their caves, including Don Coons of the Karst Conservancy of Illinois, John A. Nelzén and Shane Sellers with the Boy
Scouts of America, Joseph "Mic" Middleton with the Illinois Department of Natural Resources, Stolle Quarry (especially John Cramer), Thomas A. LeChien and Katie Feigenbutz of the Amber Waves Land Trust, Bob and Nancy Weck, Raymond and Kathleen Marchwinski, and Paul Free. Kelly Neal (Illinois Nature Preserves Commission) worked closely with us on permits necessary to carry out this work. John Lovaas, Mona Colburn, Bob Weck, Frank Wilhelm, and Philip Moss of the Illinois Speleological Survey provided access to details of cave locations and maps. The Illinois Endangered Species Protection Board provided funding to cover travel costs, laboratory supplies, and laboratory assistance.

\section{REFERENCES}

Babenko, A.B., Chernova, N.M., Potapov, M.B., and Stebaeva, S.K., 1994, Collembola of Russia and Adjacent Countries, Family Hypogastruridae, Moscow, Nauka, 336 p. In Russian.

Barr, T.C, Jr., 1963, Studies on the cavernicole Ptomaphagus of the United States (Coleoptera: Catopidae): Psyche, v. 70, p. 50-58.

Barr, T.C., Jr., 1968, Ecological studies in the Mammoth Cave System of Kentucky: I. The biota: International Journal of Speleology, v. 3, p. 147-204.

Betsch, J.-M., and Waller, A., 1994, Chaetotaxic nomenclature of the head, thorax and abdomen in Symphypleona (Insecta: Collembola): Acta Zoologica Fennica, v. 195, p. 5-12.

Bonet, F., 1947, (1948), Monografía de la familia Neelidae (Collembola): Revista de la Sociedad Mexicana de Historia Natural, v. 8, p. 131-192.

Bretfeld, G., 1999, Synopses on Palearctic Collembola. Volume 2. Symphypleona: Staatliches Museum für Naturkunde Görlitz, Abhandlungen und Berichte des Naturkundemuseums Görlitz, v. 71, 318 p.

Chen, Jian-Xiu, and Christiansen, K.A., 1993, The genus Sinella with special reference to Sinella s.s. (Collembola: Entomobryidae) of China: Oriental Insects, v. 27, p. 1-54. doi:10.1080/00305316.1993. 10432236.

Chen, Jian-Xiu, and Christiansen, K.A., 1997, Subgenus Coecobrya of the Genus Sinella (Collembola: Entomobryidae) with special reference to the species of China: Annals of the Entomological Society of America, v. 90 , p. $1-19$.

Christiansen, K.A., 1964, A revision of the Nearctic members of the genus Tomocerus (Collembola Entomobryidae): Revue d'Écologie et Biologie du Sol, v. 1, p. 639-677.

Christiansen, K.A., 2012, Ken Christiansen Collembola Collection: Grinnell College, Grinnell, Iowa. http://web.grinnell.edu/courses/bio/ collembola/maintable_menu.asp [accessed January 31, 2012].

Christiansen, K.A., and Bellinger, P.F., 1980, The Collembola of North America north of the Rio Grande, a taxonomic analysis, first edition, Grinnell, Iowa, Grinnell College, $1322 \mathrm{p}$.

Christiansen, K.A., and Bellinger, P.F., 1998, The Collembola of North America north of the Rio Grande, a taxonomic analysis, second edition, Grinnell, Iowa, Grinnell College, 1518 p.

Christiansen, K.A., and Culver, D.C., 1987, Biogeography and distribution of cave Collembola: Journal of Biogeography, v. 14, p. 459-477.

Culver, D.C., and Pipan, T., 2009, The Biology of Caves and Other Subterranean Habitats, Oxford, Oxford University Press, 254 p.

Felderhoff, K.L., Bernard, E.C., and Moulton, J.K., 2010, Survey of Pogonognathellus Börner (Collembola: Tomoceridae) in the southern Appalachians based on morphological and molecular data: Annals of the Entomological Society of America, v. 103, p. 472-491. doi:10. 1603/AN09105.

Fjellberg, A., 1984, Collembola from the Colorado Front Range, U.S.A.: Arctic and Alpine Research, v. 16, p. 193-208.

Fjellberg, A., 1985, Arctic Collembola I-Alaskan Collembola of the Families Poduridae, Hypogastruridae, Odontellidae, Brachystomellidae and Neanuridae, Entomologica Scandinavica Supplement, no. 21, $126 \mathrm{p}$. 
Fjellberg, A., 1998, The Collembola of Fennoscandia and Denmark. Part I: Poduromorpha, Leiden, Brill Academic Publisher, Fauna Entomologica Scandinavica series 35, $184 \mathrm{p}$.

Fjellberg, A., 2007, The Collembola of Fennoscandia and Denmark. Part II. Entomobryomorpha and Symphypleona, Leiden, Brill Academic Publisher, Fauna Entomologica Scandinavica series 42, 266 p.

Gisin, H., 1947, Sur les insectes Aptérygotes du Parc Nacional Suisse. Espèces et groupements euédaphiques: Résultats des recherches scientifiques entreprises au Parc National suisse, v. 2, p. 75-91.

Jordana, R., Arbea, J.I., Simón, C., and Luciáñez, M.J., 1997, Collembola, Poduromorpha: Madrid, Museo Nacional de Ciencias Naturales, Consejo Superior de Investigaciones Científicas, series Fauna Ibérica, v. 8, 807 p.

Lewis, J.J., Moss, P., Tecic, D., and Nelson, M.E., 2003, A conservation focused inventory of subterranean invertebrates of the southwest Illinois karst: Journal of Cave and Karst Studies, v. 65, p. 9-21.

Mari Mutt, J.A., and Bellinger, P.F., 1990, A Catalog of the Neotropical Collembola, Including Nearctic Areas of Mexico, Gainsville, Florida, Sandhill Crane Press, series Flora and Fauna Handbook no. 5, 237 p.

Master, L., Faber-Langendoen, D., Bittman, R., Hammerson, G.A., Heidel, B., Nichols, J., Ramsay, L., and Tomaino, A., 2009, NatureServe Conservation Status Assessments: Factors for Assessing Extinction Risk, Arlington, Virginia, NatureServe, 57 p.

Panno, S.V., Weibel, C.P., and Li, W., 1997, Karst regions of Illinois, Champaign, Illinois State Geological Survey, open file series 1997-2, 42 p.

Park, Kyung-Hwa, Bernard, E.C., and Moulton, J.K., 2011, Three new species of Pogonognathellus (Collembola: Tomoceridae) from North America: Zootaxa, v. 3070, p. 1-14.

Pomorski, R.J., Furgoł, M., and Christiansen, K.A., 2009, Review of North American species of the genus Onychiurus (Collembola: Onychiuridae), with a description of four new species from caves: Annals of the Entomological Society of America, v. 102, p. 1037-1049. doi:10.1603/008.102.0612.

Potapow, M., 2001, Synopses on Palearctic Collembola. Volume 3. Isotomidae: Staatliches Museum für Naturkunde Görlitz, Abhandlungen und Berichte des Naturkundemuseums Görlitz, v. 73, 603 p.

Skarżyński, D., 2005, Taxonomy of the ceratophysellan lineage (Collembola: Hypogastruridae) in the light of laboratory hybridization studies: Zootaxa, v. 1043, p. 47-59.
Skarżyński, D., 2007, A redescription of Ceratophysella lucifuga (Packard) (Collembola, Hypogastruridae) from North American caves: Journal of Cave and Karst Studies, v. 69, p. 275-278.

Sket, B., 2008, Can we agree on an ecological classification of subterranean animals?: Journal of Natural History, v. 42, p. 15491563. doi:10.1080/00222930801995762.

Soto-Adames, F.N., 2010, Two new species and descriptive notes for five Pseudosinella species (Hexapoda: Collembola: Entomobryidae) from West Virginian (USA) caves: Zootaxa, v. 2331, p. 1-34.

Stach, J., 1945, The species of genus Arrhopalites Börn occurring in European caves, Academia Polona Litterarum et Scientarium, Acta Musei Historia Naturalis no. 1, 47 p. + plates.

Szeptycki, A., 1979, Chaetotaxy of the Entomobryidae and its phylogenetical significance. Morpho-systematic studies of Collembola, IV, Kraków, Polska Akademia Nauk, Zakład Zoologii Systematycznej i Doświadczalnej, 219 p.

Therrien, F., Changnon, M., and Hébert, C., 1999, Liste des espèces de Collemboles du Québec: Bulletin de l'entomofaune, v. 21, p. 8-11.

Thibaud, J.-M., Schulz, H.-J., and da Gama Assalino, M.M., 2004, Synopses on Palearctic Collembola. Volume 4. Hypogastruridae: Staatliches Museum für Naturkunde Görlitz, Abhandlungen und Berichte des Naturkundemuseums Görlitz, v. 75, 287 p.

Vargovitsh, R., 2009, New cave Arrhopalitidae (Collembola: Symphypleona) from the Crimea (Ukraine): Zootaxa, v. 2047, p. 1-47.

Waltz, R.D., and Hart, J.W., 1996, A checklist of the Indiana Collembola (Hexapoda): Proceedings of the Indianan Academy of Science, v. 105, p. 29-41.

Weibel, C.P., and Panno, S.V., 1997, Karst Terrains and Carbonate Bedrock in Illinois, Champaign, Illinois State Geological Survey, Illinois map 8, 1:500000.

Wray, D.L., 1950, Some new Nearctic Collembola: Psyche, v. 57, p. $95-100+1$ plate. doi: $10.1155 / 1950 / 65134$.

Zeppelini, D., and Christiansen, K.A., 2003, Arrhopalites (Collembola: Arrhopalitidae) in U.S. caves, with the description of seven new species: Journal of Cave and Karst Studies, v. 65, p. 36-42.

Zeppelini, D., Taylor, S.J., and Slay, M.E., 2009, Cave Pygmarrhopalites Vargovitsh, 2009 (Collembola, Symphypleona, Arrhopalitidae) in United States: Zootaxa, v. 2204, p. 1-18. 